\title{
Case Studies of Seismic Energy Release Ahead of Underground Coal Mining Before Strong Tremors
}

\author{
Maciej J. Mendecki, ${ }^{1}$ (D) Lukasz Wojtecki, $^{2}$ and Wacław M. Zuberek ${ }^{1}$
}

\begin{abstract}
We would like to test the concept that induced seismicity prior to relatively large mining tremor $\left(\mathrm{M}_{\mathrm{L}}>2.5\right.$, E $\left.>10^{6} \mathrm{~J}\right)$ can be inferred from the cumulative Benioff strain release (BSR) as power law time-to-failure before the strong event. This study presents the application of accelerating BSR prior to a large earthquake, widely used in natural seismicity, for analysis of this phenomenon in induced seismicity. The Benioff strain release is quantified as accelerated releases of cumulative (square root sum) of seismic energy in the time series. During the study, five sequences were extracted from the seismic catalogues from two Polish hard coal mines: exhausted Bobrek Mine (data form the ISEPOS Platform) and from a mine belonging to the Polish Mining Group. Next, a search radius was used to select precursory events and to indicate the type of processes occurring in the coal seam and its vicinity. The fitted power law of cumulative Benioff strain release showed changes of $m$-parameter. If the value of $m$ was lower than 1.0, the process was regarded as an accelerating-like and if $m$ was higher than 1.0-as a quiescence-like. The investigation of $m$-parameter vs. the search radius showed the general behaviour of the rock mass in the studied areas and allowed to evaluate the relationship between the critical radius and magnitude of the target event. The obtained scaling relation $\log (R c) \sim 0.35 \mathrm{M}_{\mathrm{L}}$ is similar to these reported by other authors who analysed natural seismicity which might suggest that the scaling relation works in a wide range of magnitudes.
\end{abstract}

Key words: Benioff strain release, induced seismicity, preshock sequence, mining, Upper Silesia Coal Basin.

\section{Introduction}

Accelerating energy release (AER), accelerating moment release (AMR) or Benioff strain release (BSR) represent the critical-point-like models of natural earthquakes. The model of AER (or AMR, or

1 Faculty of Earth Sciences, University of Silesia in Katowice, Bedzinska 60, 41-200 Sosnowiec, Poland. E-mail: maciej.mendecki@us.edu.pl

2 Central Mining Institute, Gwarków 1, 40-166 Katowice,
BSR) proposes that before a large event, seismic activity in the surrounding region of the event can show the property of accelerating behaviour as power law (Jiang and $\mathrm{Wu} 2005$ ).

The critical-point-like model, also known as timeto-failure method, originated from equation used to describe the fracture growth and a catastrophe which occurs if the cracks becomes critical and propagate dynamically in a nucleation phase. This phase is characterised by a tectonic loading process consisting of a steady increase in the applied stress that is finally released by the earthquake. Because of the accelerating nature of the nucleation process, the probability for foreshocks to occur increases very rapidly as the time approaches the time of the main shock. Moreover, foreshocks are not an intrinsic part of the nucleation process, so they are not required to fit any regular pattern, nor are all earthquakes required to have foreshocks. This suggests that the study of any pre-shocks may provide information concerning the spatial and temporal development of the nucleation phase (Das and Scholz 1981).

Many works were focused on the time to-failure analysis and intermediate-term prediction of strong events concerning natural seismicity: i.e. in California (e.g.: Sykes and Jaumé 1990; Bowman et al. 1998; Gross and Rundle 1998; Brehm and Braile 1999; Jaumé and Sykes 1999), Missourii (Brehm and Braile 1998), Greece, Japan and Mexico (Varnes 1989), Indonesia (Jiang and Wu 2005), China (e.g.: Jiang and Wu 2006) or Himalaya and Caribbean Sea (Kawada and Nagahama 2006) and many others (Mignan 2011). Moreover, Jaumé and Sykes (1999) introduced in their work the historical background of this approach to deal with the prediction of strong earthquakes using AER, AMR or BSR. A number of Poland. 
authors have also studied the spatial changes of AER/ AMR/BSR according to the range of the searching radius, indicating whether the process of acceleration occurred or not in the vicinity of the target tremor focus (e.g.: Bowman et al. 1998; Jiang and Wu 2006; and works cited there), and statistical tests were introduced to assess the intermediate-term prediction of a strong event (e.g. Brehm and Braile 1999; Gross and Rundle 1998).

The AER/AMR/BSR model can be originated independently from the works of Das and Scholz (1981) and Voight (1989). Brehm and Braile (1999) showed that the same AER/AMR/BSR model can be obtained from the assumptions described by Das and Scholz (1981). But in this case, the model was derived from fracture mechanics and crack propagation based on the Das and Scholz (1981) equation which considers relation between the rate of crack half-length, stress drop, stress intensity factor, crack velocity and stress corrosion index. Another formula describes the behaviour of materials in terminal stages of failure under conditions of approximately constant stress and temperature, and it can be presented as follows (Voight 1989):

$$
\dot{\Omega}^{-\alpha} \ddot{\Omega}-A=0,
$$

where A and $\alpha$ are constants and $\Omega$ is an appropriate measurable quantity, dots above the symbols denote time derivatives (Voight 1989; Sykes and Jaumé 1990). In the discussed cases, $\Omega$ denoted the AMR, AER or Benioff strain-release. The acceleration energy release or Benioff strain-release is defined as the sum of the square root of the energy release for sequential earthquakes (Kawada and Nagahama 2006) and the acceleration moment release is the cumulative seismic moment release (Brehm and Braile 1998).

Similar equation to (1) can be found in the works of Varnes (1983, 1989). In these cases (Voight 1989; Varnes 1989), the solution reported for the first derivative of $\Omega$ over time, $t$, is expressed as (Vallianatos and Chatzopoulos 2018):

$$
\dot{\Omega}=\frac{k}{\left(t_{f}-t\right)^{n}} .
$$

where $k$ and $n$ are constants, $t_{f}$ is the time of failure and dots over symbols denote time derivatives.
Therefore, the model proposed for the rate at which seismic energy or moment is released during an earthquake sequence before a strong event is (Varnes 1989; Bowman et al. 1998; Brehm and Braile 1998, 1999; Jiang and Wu 2006):

$$
\Sigma \Omega=K-\frac{k}{n-1}\left(t_{f}-t\right)^{m} .
$$

In which $\Omega$ is a measure of seismic activity from earthquakes energy, magnitude or moment, $K, k$ and $n(n \neq 1)$ are constants, $m=1-n$ is the scaling factor, and $t_{f}$ is the time of failure (strong event to be considered- "target" tremor). Equation (3) is an integral over time of Eq. (2). Moreover, Eq. (3) is solved for three unknowns $(K, k$, and $m)$, while $t_{f}$ is taken as the time of the "target tremor".

Some authors consider the solution of Eq. (3) for the different search radiuses (e.g.: Bowman et al. 1998; Jiang and Wu 2005, 2006). This approach can compare different "target" earthquakes using variable searching areas (circles with the search radius) around the "target" earthquakes in the considered period of time. The circular searching areas are centred at the epicentre of the "target" earthquake used for the analysis. Jiang and Wu (2005, 2006) discussed the details of such a nonlinear fitting in the circular areas to efficiently avoid the effect of local minima and increase the stability of the solution. By definition, if the value of $m$ is lower than 1.0, the release curve is regarded as an accelerating-like; if $m$ is higher than 1.0, then the release curve is regarded as a quiescence-like. Moreover, a systematic method for selecting the optimum search radius and identifying the range in the search radius was developed and presented by Brehm and Braile (1998) and papers referred there. The process of AER/AMR/ BSR for natural earthquakes has to fulfil two criteria for the precursory sequence: (1) the record of events is complete for an appropriate time interval preceding the main shock, where a complete record must contain all events within approximately two magnitudes of the mainshock magnitude (i.e., it has a linear magnitude-frequency relationship); (2) there are no interfering events which are events that occur within the same time period and location, and have similar or greater magnitudes (generally within one magnitude unit) (Brehm and Braile 1998). 
In the works mentioned above, the authors indicated that the AER/AMR/BSR can be successfully used in the study of pre-earthquake sequences to predict the main shock or to distinguish rock mass behaviour as an accelerating-like and a quiescencelike type. In this paper, we adopted the described assumptions and relations to relative strong events observed during underground mining exploitation. The study was carried out for two Polish hard coal mines: exhausted Bobrek Mine (data obtained from the IS-EPOS platform) and from a still operating one belonging to the Polish Mining Group (data obtained from PMG mine seismic catalogue), located in the Upper Silesia Coal Basin (USCB), the main anticline, Southern Poland (Fig. 1).

\section{Assumptions Regarding the Application of AER/ AMR/BSR in Mines}

Gibowicz and Kijko (1994) stated that the methods and techniques employed to study seismicity in mines can be transferred directly from earthquake seismology (natural seismicity). In general, seismicity in underground mines is affected by several factors such as depth and type of the rock mass, production output, mining system and geometry, geologic structure, and geologic discontinuities (Gibowicz and Kijko 1994) as well as mining edges, gobs and other operating longwall fields (Wojtecki et al. 2016) resulting in occurrence of induced or triggered seismicity. Seismicity induced by mining is usually defined as the appearance of seismic events

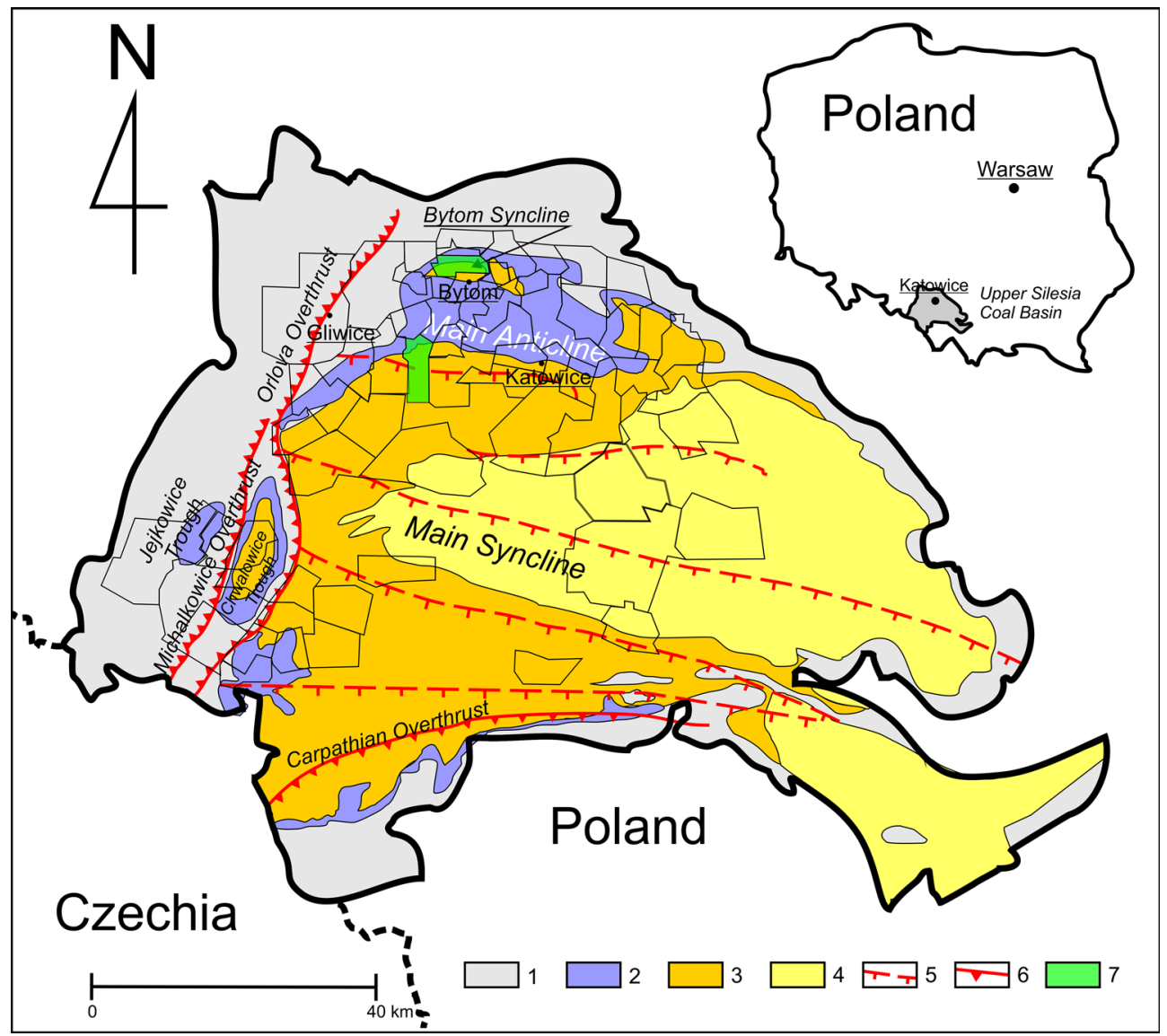

Figure 1

Lithostratigraphy and tectonics of the USCB: 1-Paralic Series (upper Mississippian-lower Pennsylvanian), 2-Upper Silesian Sandstone Series (lower Pennsylvanian), 3-Mudstone Series (lower-middle Pennsylvanian), 4-Krakow Sandstone Series (middle Pennsylvanian), 5important faults, 6-overthrusts, 7—studied areas (modified after Kędzior 2015) 
caused by rock failures being a result of changes in the stress field in the rock mass near mining excavations. Triggered seismicity can be defined as seismicity regarding larger events on nearby active tectonic faults which is activated by human input (Mulargia and Bizzarri 2014). Induced seismicity can be distinguished (discriminated) from the triggered seismicity using: (1) probabilistic discrimination scheme (physics-based probabilistic model) based on the modelling of depletion-induced stress changes and seismological source parameters (Dahm et al. 2015); (2) source parameter approach for collapsetype events using full moment tensor inversion and decomposition (Cesca et al. 2013; Lizurek 2017); and statistics-based seismicity model (Dahm et al. 2013). Detailed discussion of present state of natural and anthropogenic (triggered and induced) seismicity can be found in the work of Grigoli et al. (2017) in which challenges in discriminating induced/triggered from natural seismicity were widely discussed.

In this study we assumed that Benioff strain release is relating to induced/triggered seismicity. Before a strong event the BSR can cause and increase of stress state in rock mass and lead to interaction between mining stresses and residual tectonic stresses. Gibowicz (2006) found that in a wide range of magnitudes, from 0.7 to 3.5 , the occurrence of mining-induced seismic events can increase the probability of the next event. Therefore, the area around the given longwall field (or even a mine) can be treated as a combined system of fractures, faults, low- and high-velocity zones allowing for stress transfer.

According to the criteria presented by Brehm and Braile (1998) for natural seismicity: complete catalogue and a lack of interfering events, we adopted the same criteria in the calculation, i.e. (1) the magnitude of completeness $(M c)$ must be known, and the data set should have a frequency-magnitude distribution (FMD) for an appropriate time interval preceding the main shock; and (2) there are no interfering events either. The main shocks (large mining events) were chosen based on the assumption that the strong event has usually a greater local magnitude than the background which can be represented by an event swarm ranging from $M c$ to $M_{L} 2.0-M_{L} 2.5$. In the Upper Silesia Coal Basin, this corresponds to energies ranging from $E_{\text {min }}$ to $10^{5}-10^{6} \mathrm{~J}$. The $M c$ or $E_{\text {min }}$ represents a threshold of the seismic catalogue completeness. The strong event can be characterized by higher energies: $10^{7}-10^{8} \mathrm{~J}$ and even $10^{9} \mathrm{~J}$, corresponding to the local magnitudes of 3.0-3.5 and 4.0, respectively. This assumption is based on the statistics of large events in the Upper Silesia Coal Basin reported by Stec (2007) and Marcak and Mutke (2013). Moreover, the choice of the strongest event was dictated by the individual statistics of each catalogue and the ranges of data that were chosen arbitrarily to meet the criterion of completeness and the absence of interfering events.

\section{Sites Characterization}

The USCB in southern Poland is a place of intense coal exploitation carried out since the eighteenth century. Coal seams deposited within Carboniferous sandstones, conglomerates and mudstones are now being exploited in more than thirty mines using the longwall method (Kozłowska et al. 2016). To test our ideas about AER/AMR/BSR in mines, we have chosen two mines from the USCB area: Bobrek mine and an operating mine belonging to the Polish Mining Group (PMG). Due to legal reason, the name of the latter cannot be presented. In the paper, the mine located in the Mine Anticline is denoted as the PMG mine.

\subsection{Bobrek Coal Mine}

The Bobrek Mine is located in the Bytom Syncline area (Fig. 1), in the northern part of the USCB and this mine is one of the primary mines in the syncline area. The Bytom Syncline composes of intense sedimentation deposits from the end of the Carboniferous Period and they are represented by: sandstone, mudstone, shell and conglomerate layers with a total thickness of a few kilometres interbedded with coal layers. This complex was subjected to folding producing a syncline with relatively steeply dipping limbs. After the Carboniferous Period, the syncline was covered by Triassic and Quaternary deposits (Marcak and Mutke 2013). The syncline is a complex asymmetrical structure consisting of series 
of shallow Brach synclines, separated by a domeshaped upthrust running NW-SE. The latitudinal axis runs from the west to the east, near the north-eastern wing resulting in that the northern wing is characterised by smaller dip angles (up to $17^{\circ}$ to the south) in relation to the opposite southern wing, where the dip angle locally reaches even $50^{\circ}$. The Syncline is also disturbed by the fault systems running mainly in the NW-SE direction (Patyńska and Stec 2017). What is more, mining in this area is connected mainly with occurrence of coal deposits, however the lead exploitation was conducted earlier there as well (Frej and Zuberek 2008).

The observations discussed in the paper were related to the excavation of 503 coal seam, panel 3 (Fig. 2). This excavation is located $700 \mathrm{~m}$ below the ground surface, which is $400 \mathrm{~m}$ below sea level and coal seam thickness reached 3.0-3.5 m (Marcak and Mutke 2013). Beyond the southern terminus line of the longwall excavation, the geological layers in the sideslope of the basin dip steeply. The operating along studied panel progressed from north to south, perpendicularly to the axis of the Bytom Syncline and produces relatively high seismicity which was monitored by a seismic network consisting of 12 shortperiod seismometers: 7 vertical and 5 three component sensors (Kozlowska and Orlecka-Sikora 2017). The seismic activity was relatively minor during the initial phase of the longwall excavation and it increased when the excavation approached the syncline axis. Moreover, factors producing strong seismic events were related to prior mining over the exposed seam, leaving abutments and remnants, irregular excavation of the deposit and advancing

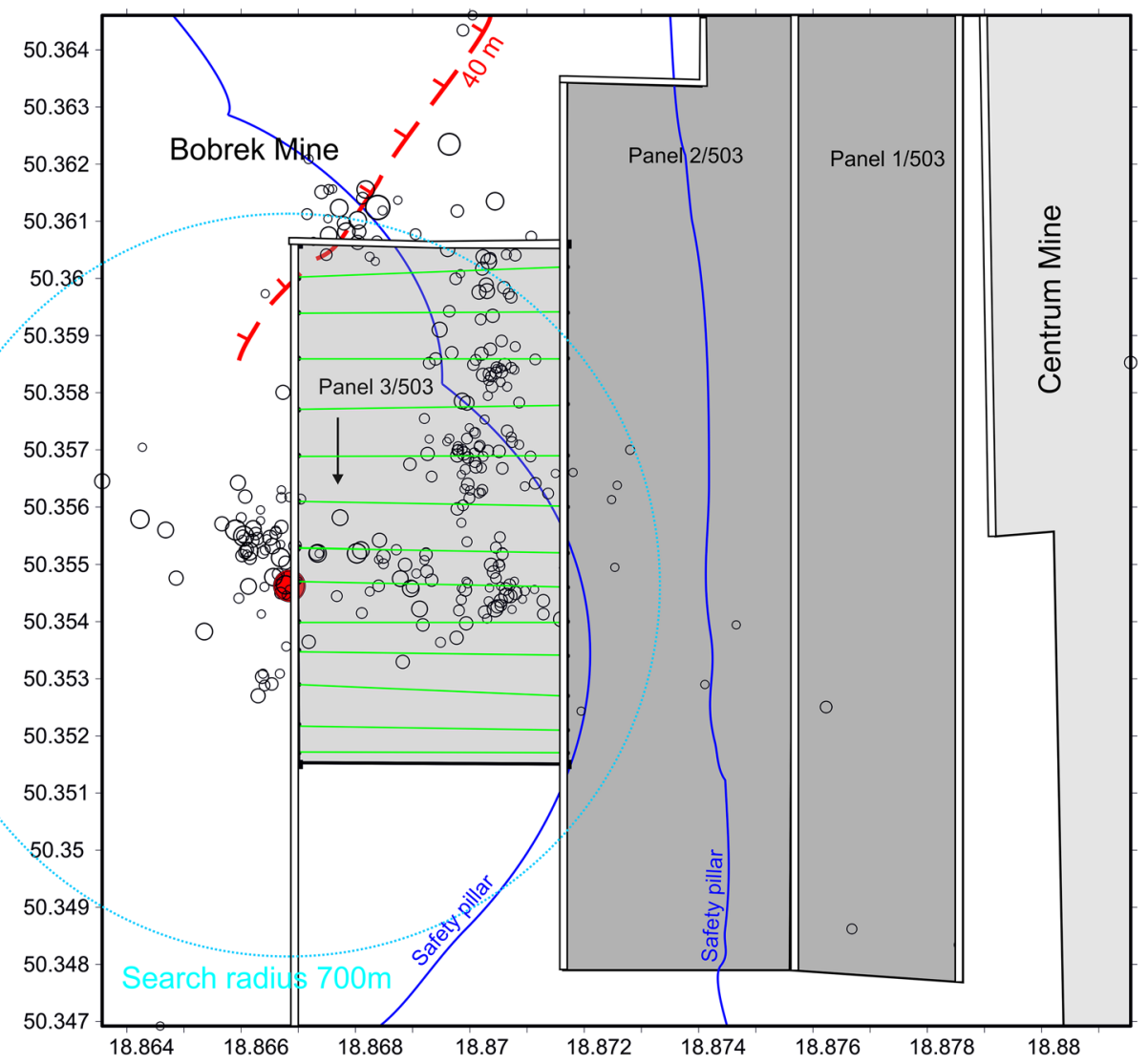

Figure 2

Mining conditions in panel no. 3/503, Bobrek Mine, circles are tremors (red circle-target event), green lines are longwall face advances, red dashed lines-faults, grey areas_longwall fields (after Mutke and Pierzyna 2011) 
the longwall excavation fronts in seam 503 to approach the slope of the Zabrze Dome and the protection pillars of the primary shafts of the Bobrek Mine (Marcak and Mutke 2013).

\section{2. $P M G$ Mine}

The selected hard coal mine, belonging to the Polish Mining Group, is located at the Main Anticline of the Upper Silesia Coal Basin (Fig. 1). This mine is divided by the Klodnicki fault into two parts: North and South. Extraction of coal seams belonging to the 500 's series were carried out in the northern part of Klodnicki fault and from this side the data were recorded during excavation of coal seam 504 (Fig. 3). Oppositely, in the southern part there are located seams belonging to the 400's series and here the panel excavated in coal seam $405 / 2$ was used in the analysis. In both cases, the extraction of the coal seams was performed under conditions of high level of seismic and rockburst hazard. Geological and mining factors affecting mostly the seismic activity and stress concentration in rock mass are similar to those in Bobrek mine i.e.: faults and folds, remnants and edges of surrounding coal seams (boundaries of exploitation made in the surrounding upper and lower coal seams) as well as pillars.

\subsubsection{Northern Part of Klodnicki Fault: Coal Seam 504}

Coal seam 504 is deposited at a depth between - 997 and $-1034 \mathrm{~m}$ below the surface and the selected-toanalysis longwall (excavated with caving) was performed mostly under a high stress level resulting in a tendency to burst. However, extraction of coal seam 506, deposited 17-27 m below coal seam 504, effectively destressed the rock mass in the area of the selected longwall. The thickness of coal seam 504 varies from ca. 4.3 to $6.4 \mathrm{~m}$ and increases to the West. The dip of coal seam 504 ranges from $2^{\circ}$ to $14^{\circ}$, mostly to the West and South-West. The direct

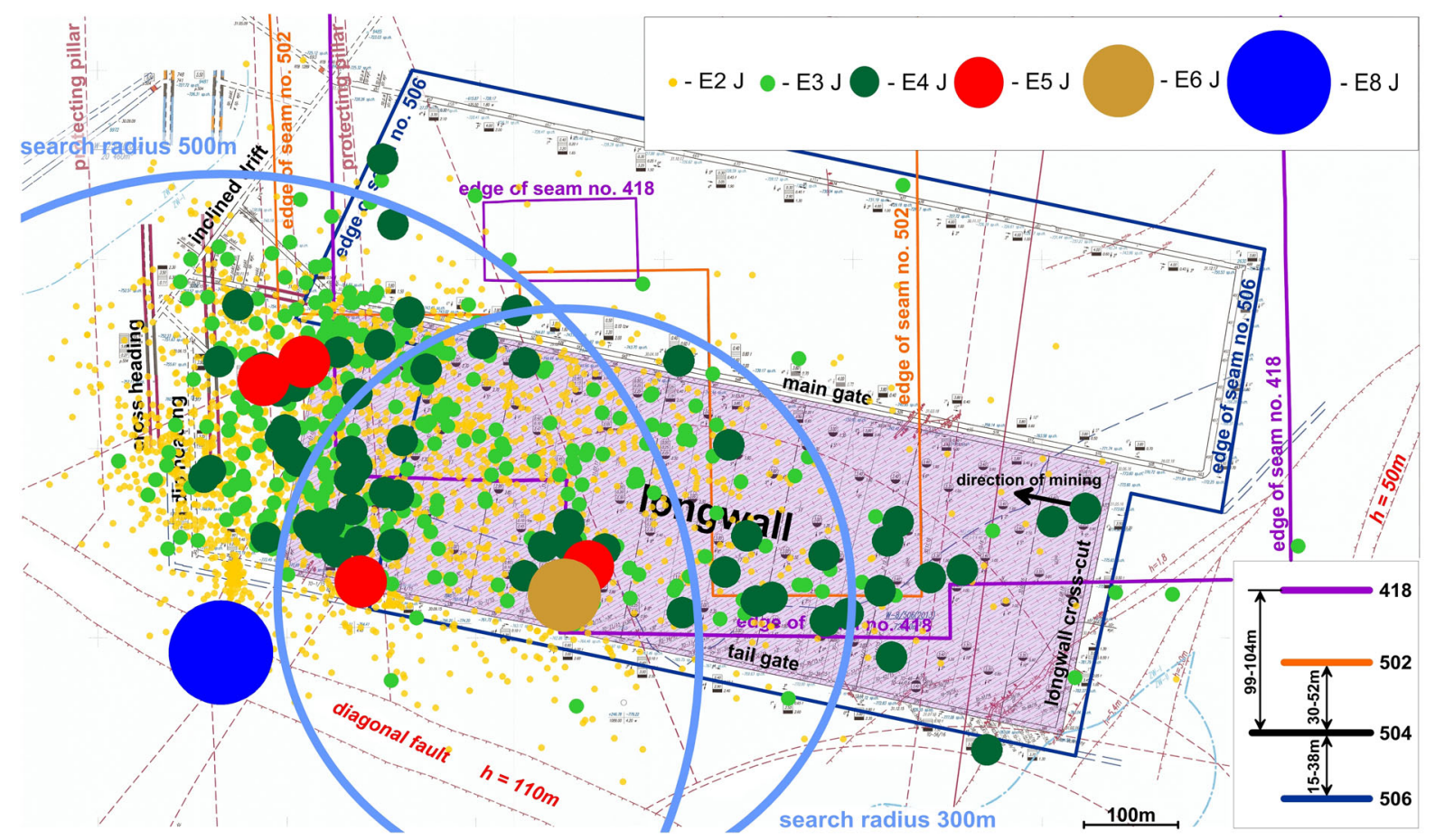

Figure 3

Mining condition in the exploited panel, coal seam 504; dots denote mining tremors with different energy/magnitude (blue $5 \times 10^{8} \mathrm{~J} / \mathrm{M}_{\mathrm{L}} 3.6$; dark yellow $9 \times 10^{6} \mathrm{~J} / \mathrm{M}_{\mathrm{L}} 2.7$, green, yellow and red other smaller tremors); straight violet, orange and blue lines denote the mining edges of other coal seams: 418, 502 and 506, respectively. Light blue corresponds to the search radius 
roof of coal seam 504 consists of alternating layers of shale, sandy shale and sandstones. The floor rock consist mostly of deposits of shales. The longwall face was moved from the East to the West, along the diagonal fault (throw $h=110 \mathrm{~m}$ ), being an arm of the Klodnicki fault. The edges of coal seams nos. 418 and 502 (99-104 $\mathrm{m}$ and $30-52 \mathrm{~m}$, respectively, above coal seam no. 504) were present in the area of the selected longwall, affecting the stress level in the roof rocks and seismic activity. The end of the longwall run was arranged to the East of the protecting pillars for drifts, in the direct neighbourhood of the diagonal fault (throw $h=110 \mathrm{~m}$ ) where the rock mass was not destressed due to presence of non-extracted coal seam 506. It resulted in the seismic activity increase and caused the strongest tremor with the energy $5 \times 10^{8} \mathrm{~J}\left(M_{L}=3.63\right)$ near the diagonal fault.

\subsubsection{Southern Part of Klodnicki Fault: Coal Seam $405 / 2$}

The selected longwall in coal seam 405/2 (Fig. 4) is located at depths ranging between $\times 975$ and $\times 1018 \mathrm{~m}$ below surface where high hydrostatic stress level (uniaxial) is produced by overburden layers and it contributes to increase of burst hazard. Additionally, the stress level increases due to separation of coal seam 405/2 into two layers: upper and lower. The spacing between these layers ranges from 0.1 to $7 \mathrm{~m}$ and the interlayer between them consists of shales and sandy shales. The dip of the coal seam ranges from $8^{\circ}$ to $16^{\circ}$, mostly to the South. The roof rocks are mostly composed of shales and sandy shales and very variable thickness of sandstones, while the floor rocks composes of shales and sandy shales, and locally sandstones as well. Near the longwall crosscut (at the beginning of longwall run), the thickest layer of sandstones in the roof reaches $8 \mathrm{~m}$ and it is deposited about $8 \mathrm{~m}$ above the studied coal seam. Near the end of the longwall run, the thickness of sandstones increases up to $12 \mathrm{~m}$ (together with the $0.7 \mathrm{~m}$ interlayer of sandy shale) and is deposited about $62 \mathrm{~m}$ above the coal seam.

The stress level disturbance in the rock mass which affected the high seismic activity is also caused by local mining and geological structures: the
Makoszowski fault (throw $h=50 \mathrm{~m}$ ) and local accompanying faults; the gob of the previous longwall mining in the coal seam 405/2 (Fig. 4), located to the North, as well as, mining edges in coal seams nos. 364/3 and 401 (215 $\mathrm{m}$ and 167-187 m, respectively, above the studied coal seam). The end of the longwall run was established on the border of the pillar for drifts, where exploitation of coal seams nos. 358/1, 361/1, 364/1 and 364/3 had been finished. After the end of the extraction of coal seam no. 405/2, an increase of seismic activity occurred due to the removal of mechanized supports resulting in occurrence of the strongest tremor with energy of $3 \bullet 10^{6} \mathrm{~J}$ $\left(M_{L}\right.$ 2.6). This tremor caused a coal bump in the inclined drift located several tens of meters to the East from the end of the selected longwall.

\section{Data Used and Methodology}

Data from three coal seams were chosen to study the acceleration Benioff strain release in mines. In each case, the seismic catalogue concerns one longwall field and the analysed period covers the time required to exploit the coal deposit existing there. Each data set was analysed in order to find the best values of minimum magnitude (completeness) and $b$ value estimation (Figs. 5, 6, 7). The first data set was obtained from the Bobrek Mine and it was available on the IS-EPOS platform (IS EPOS 2017) in the Episode: BOBREK MINE. The episode relates to seismic activity connected with longwall mining of panel 3 in coal seam 503 in the Bobrek mine in the Bytom Syncline (Fig. 1) in the Upper Silesia Coal Basin in Poland (Leptokaropoulos et al. 2017). The seismic catalogue consists of 275 events which appeared in the vicinity of panel 3 and the events were recorded since 12th April, $2009\left(M_{L} 1.2\right)$ to 16th December, 2009 when the strong event $\left(M_{L} 3.7\right)$ occurred. Within the catalogue, the magnitudes ranged from 0.1 up to 3.7 (Table 1, Fig. 5a). The magnitude of completeness (the minimum magnitude) $M_{c}=1.0$ was assessed using the goodness-of-fit approach (Wiemer and Wyss 2002; Ibáñez et al. 2012). This technique is based on calculation of the frequency-magnitude relationship for each magnitude from the low-energy range, checking the value 


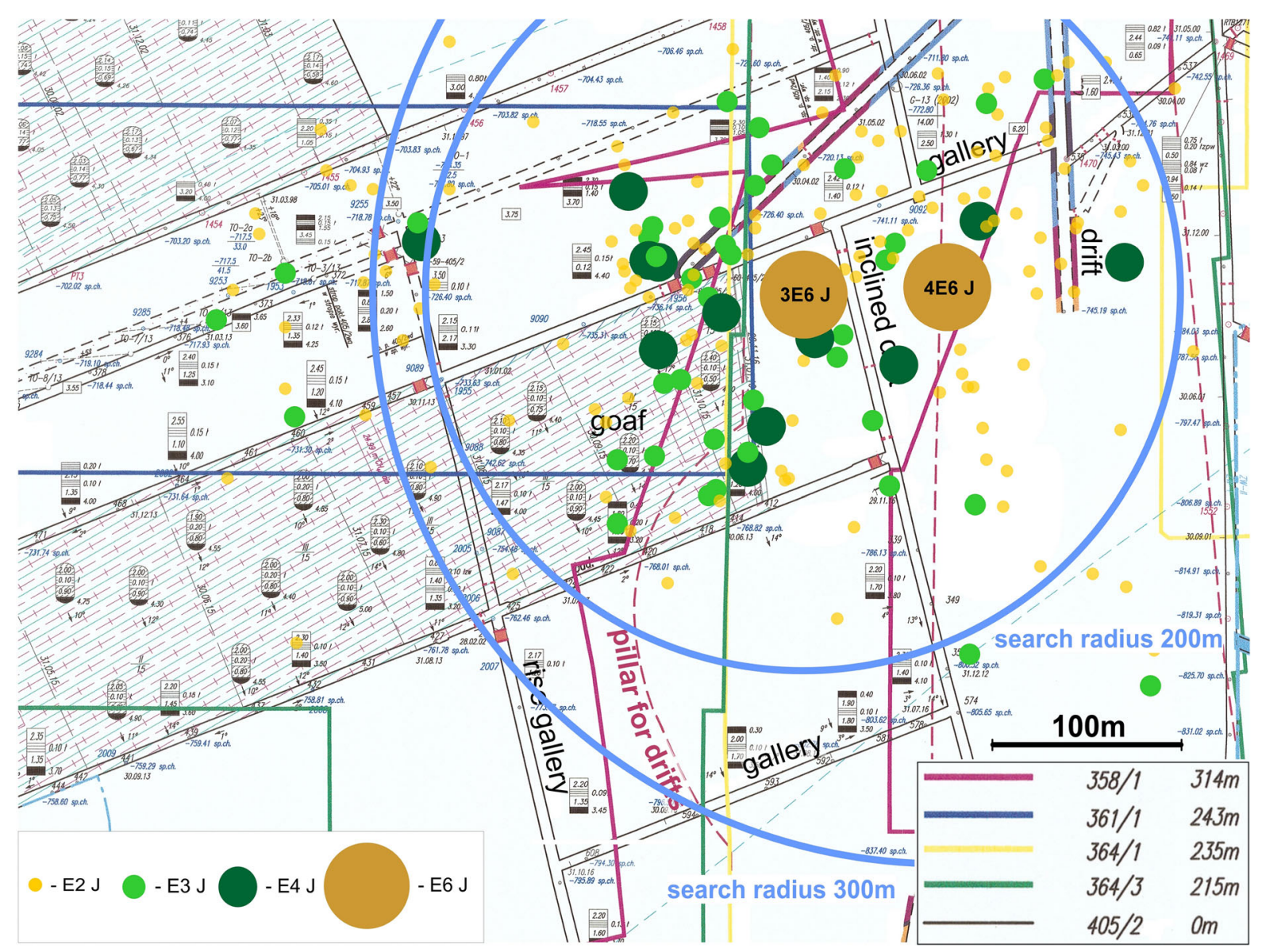

Figure 4

Mining conditions in the exploited panel 405/2 in the vicinity of the safety pillar; dots denote mining tremors with different energy/magnitude (dark yellow $4 \times 10^{6} \mathrm{~J} / \mathrm{M}_{\mathrm{L}} 2.6$; dark yellow $3 \times 10^{6} \mathrm{~J} / \mathrm{M}_{\mathrm{L}} 2.5$, green dots are other smaller tremors); straight pink lines are the pillar edges.

Light blue corresponds to the search radius

of the goodness-of-fit statistics and choosing the minimum magnitude for which the statistic is the highest. In this case, the magnitude of completeness was searched from 0.0 to 1.8 (Fig. 5d) and the highest goodness-of-fit was obtained for $\mathrm{M}_{\mathrm{c}}=0.96$ (next, rounded to 1.0) where the statistics reached the value of 0.90 . All considered frequency-magnitude models are presented as red lines in Fig. 5c. The $b$-value was 1.18 in this data set (Table 1, Fig. 5e) and was obtained for logarithmized values of cumulative frequency from Fig. 5b.

The next source of data was the PMG mine located in the Mine Anticline, the USCB (Fig. 1). There, two data sets were chosen concerning seismic events occurring before two relatively strong events located in two different coal seams (different mining conditions) on the opposite sides of Klodnicki fault.

The first set contains data of 271 events occurring before $\mathrm{M}_{\mathrm{L}} 3.6$ tremor, recoded from 30th November, 2016 to 18th January, 2018. However, due to the assumption of no interfering events, this data set was

\section{Figure 5}

Data statistics for the Bobrek Mine: a histogram of frequencymagnitude relationship, b cumulative frequencies vs. magnitude, c considered models of frequency-magnitude relationship (red lines) and d changes corresponding the goodness-of-fit with magnitudes, e comparison of the best fit of frequency-magnitude relationship (red line) with log-frequency-magnitude distribution 


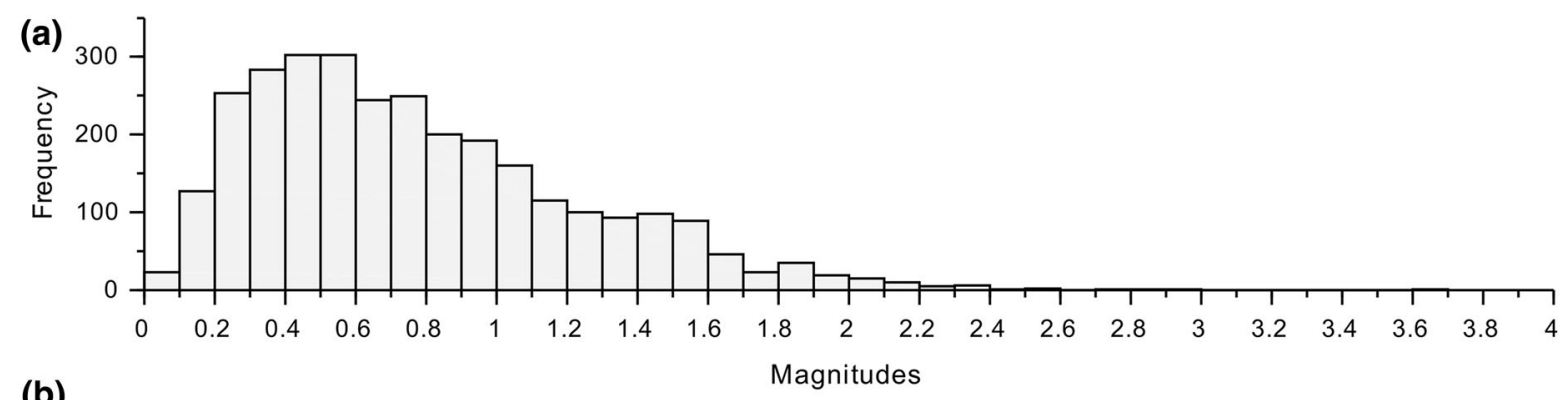

(b)

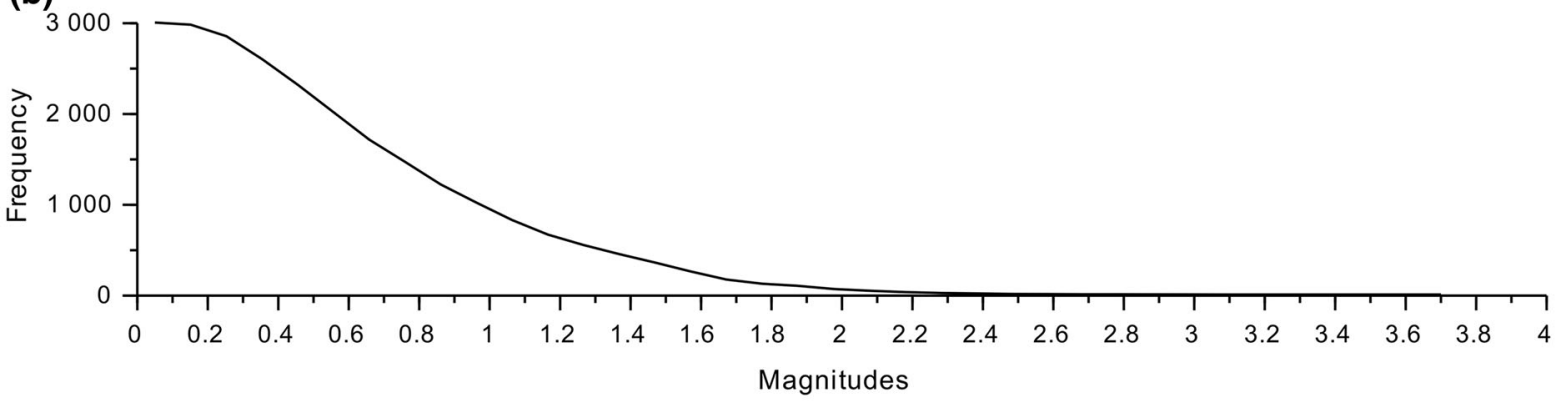

(c)

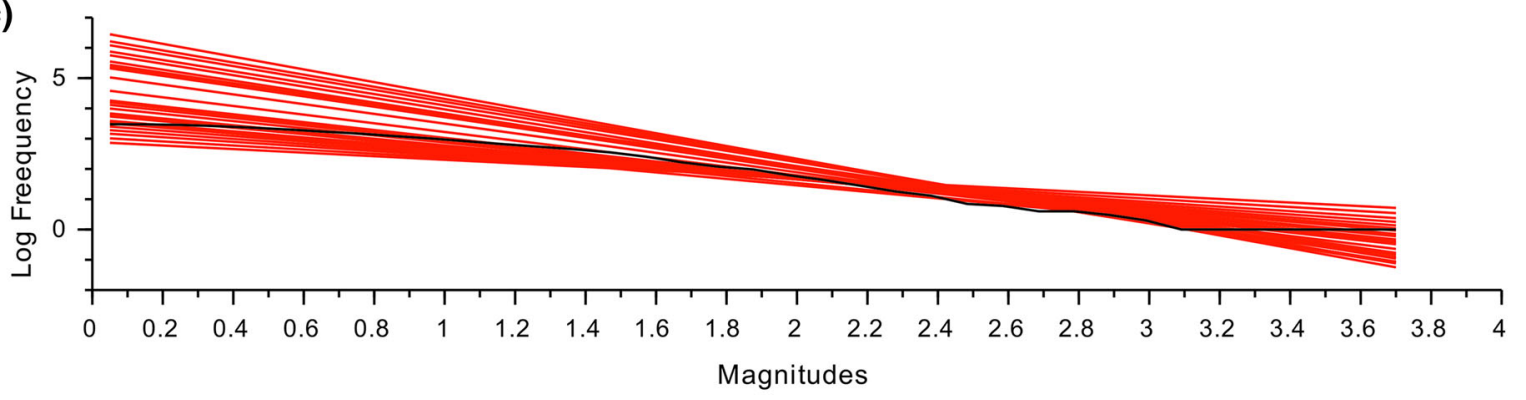

(d)

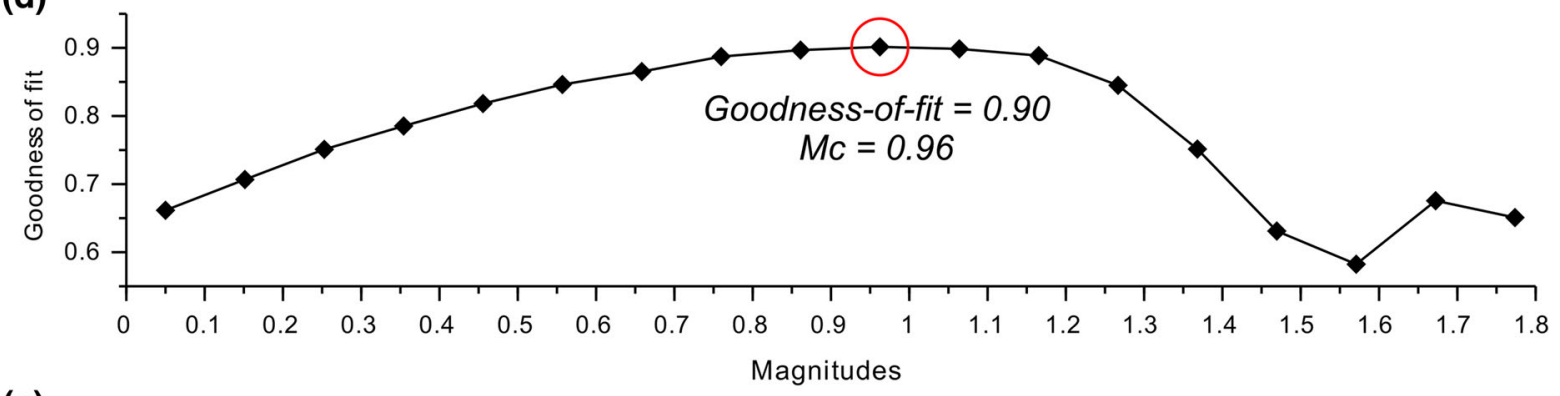

(e)

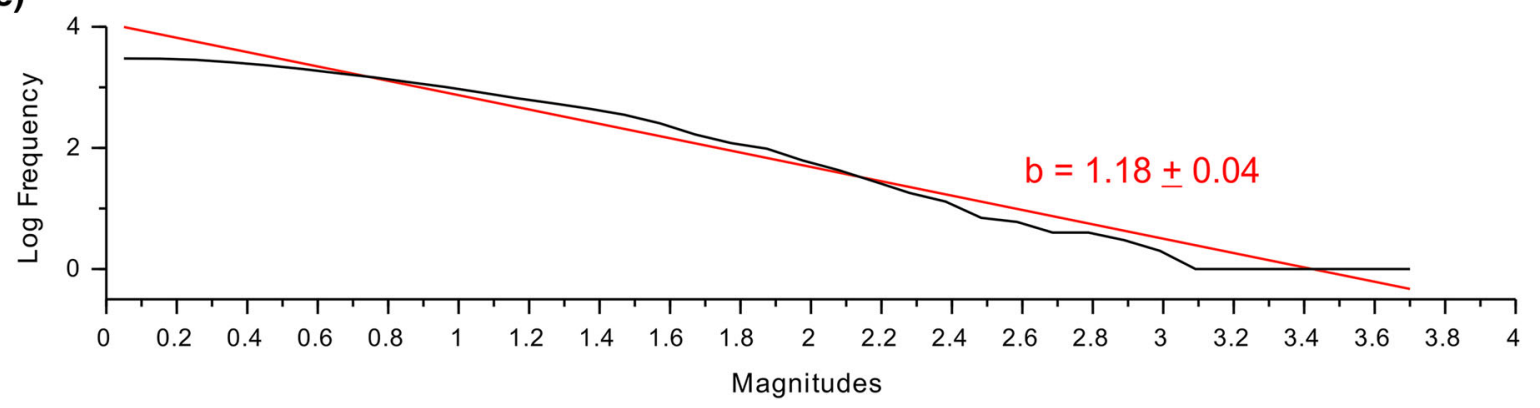



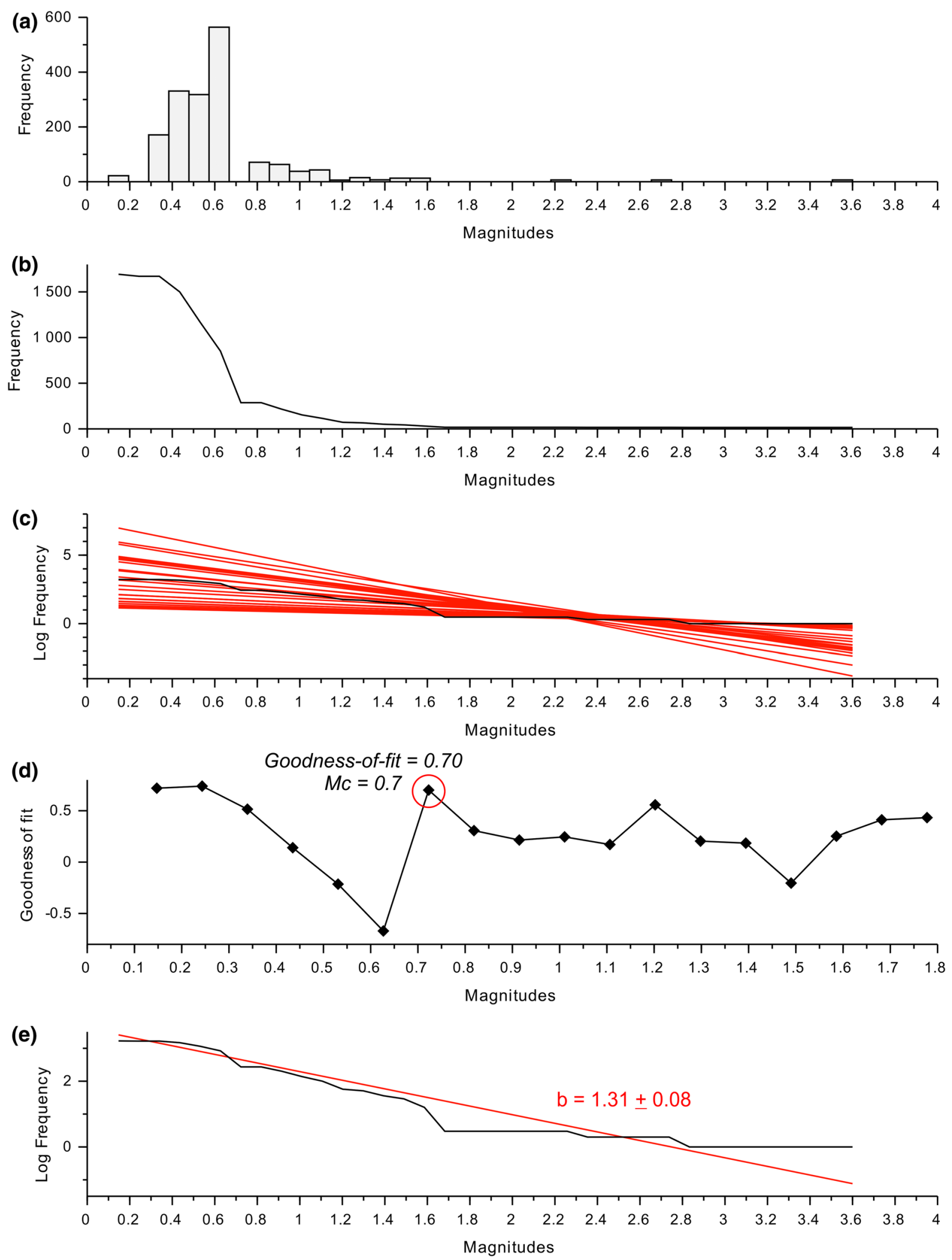
Figure 6

Data statistics for the PMG mine-the first data set: a histogram of frequency-magnitude relationship, $\mathbf{b}$ cumulative frequencies vs. magnitude, c considered models of frequency-magnitude (red lines) relationship and $\mathbf{d}$ changes corresponding the goodness-of-fit with magnitudes, e comparison of the best fit of frequencymagnitude relationship (red line) with log-frequency-magnitude distribution

split into two subsets because on 7th May, 2017 a tremor with $\mathrm{M}_{\mathrm{L}} 2.7$ appeared which disturbed the sequence. Therefore, the early sequence contains 76 events before the $\mathrm{M}_{\mathrm{L}} 2.7$ event (May, 2017) and the late sequence contains 195 events before the $\mathrm{M}_{\mathrm{L}} 3.6$ event (January, 2018). The minimum magnitude was calculated for both sub-sets and reached the value of 0.7 with 0.70 goodness-of-fit and $b$-value was 1.31 (Table 1, Fig. 6). Figure 6a shows the FMD which was used to obtained cumulative relation (Fig. 6b). Figure $6 \mathrm{c}$ contains the solutions of all considered frequency-magnitude models (red line) which were used to evaluate goodness-of-fit statistics (Fig. 6d) and to find the best one (Fig. 6e).

A similar situation was observed for the second data set from the PMG mine, recorded near the pillar. The total number of events reached 176, the recording period was from 1st January, 2016 to 29th November, 2016 and the interfering event occurred on 16th October, 2016. The first strong event was $\mathrm{M}_{\mathrm{L}}$ 2.6 (October) and the second was 2.5 (November). These two sequences contain 34 and 14 events, respectively, and the minimum magnitude was 0.8 , the goodness-of-fit was 0.9 (Fig. 7d) and $b$-value reached 1.05 (Table 1, Fig. 7e). Figure 7a, 7b shows non-cumulative and cumulative frequency-magnitude relation, respectively.

The next step was the calculation of the empirical BSR as a cumulative value of the square root of energy for different search radiuses. The last stage was to estimate the model of BSR from the Eq. (3), using the least-square method in order to obtain the following model parameters: $K, k, m$ and $n$.

Figures 6 and 7 show breakpoints in the frequency-magnitude distribution that can be result of deviation at both ends of the distribution (Amorese 2007) as well as small number of events used in analysis (see Table 1). A lack of some magnitude ranges in the catalogue caused appearance depletions in the middle part of the cumulative FMD which stand out from the main trend. This indicates that FMD in these two cases cannot follow the GutenbergRichter distribution. However, we assumed that the calculated $M_{c}$ and $b$-values can be treated as an approximation of the expected value, thus we have used them in further analysis. Moreover, getting certain values in this case is difficult mainly due to the lack of proper data statistics.

\section{Results}

\subsection{Seismic Energy Release in the Bobrek Coal Mine}

The investigation of seismic energy/Benioff strain release before the strong event in the Bobrek Mine showed that the process had an accelerating-like type sequence before the target tremor $\mathrm{M}_{\mathrm{L}}$ 3.7. The study area was divided into 5 circular areas with 100, 300, 500 and $700 \mathrm{~m}$ search radius and the total number of pre-shocks was taken into consideration (Fig. 8). For each search radius, the BSR function was calculated (Fig. 8) and it produced $m$-parameter varying in the range of 0.304-0.542 indicating that the entire study area is characterised by an accelerating-like sequence of induced seismicity. Moreover, according to Bowman et al. (1998), if the power law increases in BSR and the rupture process is analogous to a critical phase transition, the rock mass, where nucleation process occurred, can be considered a heterogeneous material. Moreover, BSR model has been associated with subcritical crack extension theory (Mignan 2011; Vallianatos and Chatzopoulos 2018) where in rocks under constant stress the small cracks expand rapidly before the occurrence of the main fracture which results in an acceleration-like process in rocks being more heterogeneous (more fractured). The condition concerning a critical phase transition in this case has to be considered. The critical point hypothesis was introduced to natural earthquakes (Bowman et al. 1998) but not to sequences induced directly by mining. By definition, the critical behaviour is a cooperation between "microscopic" 


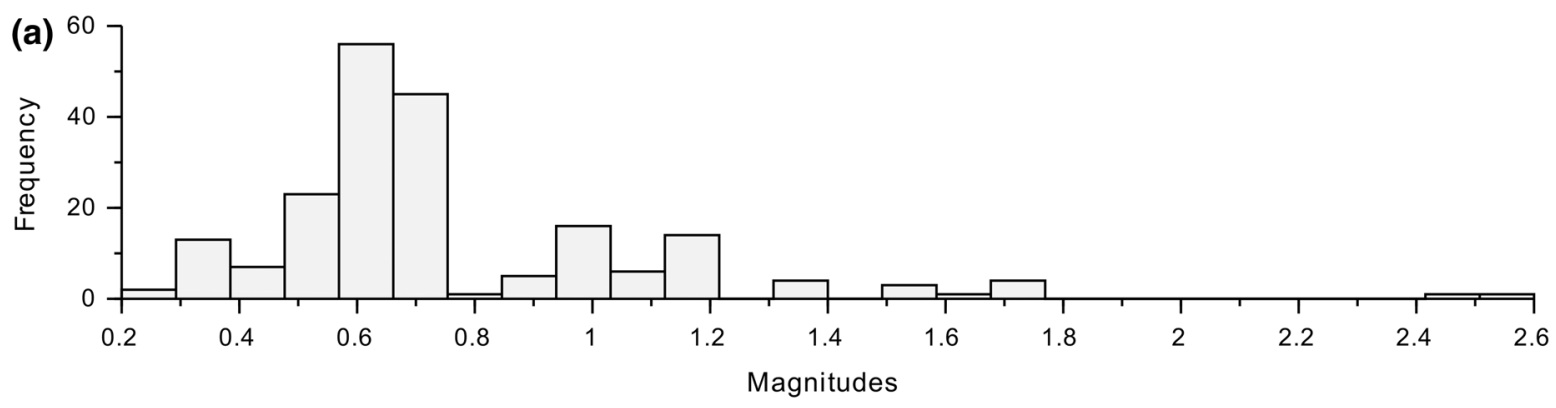

(b)
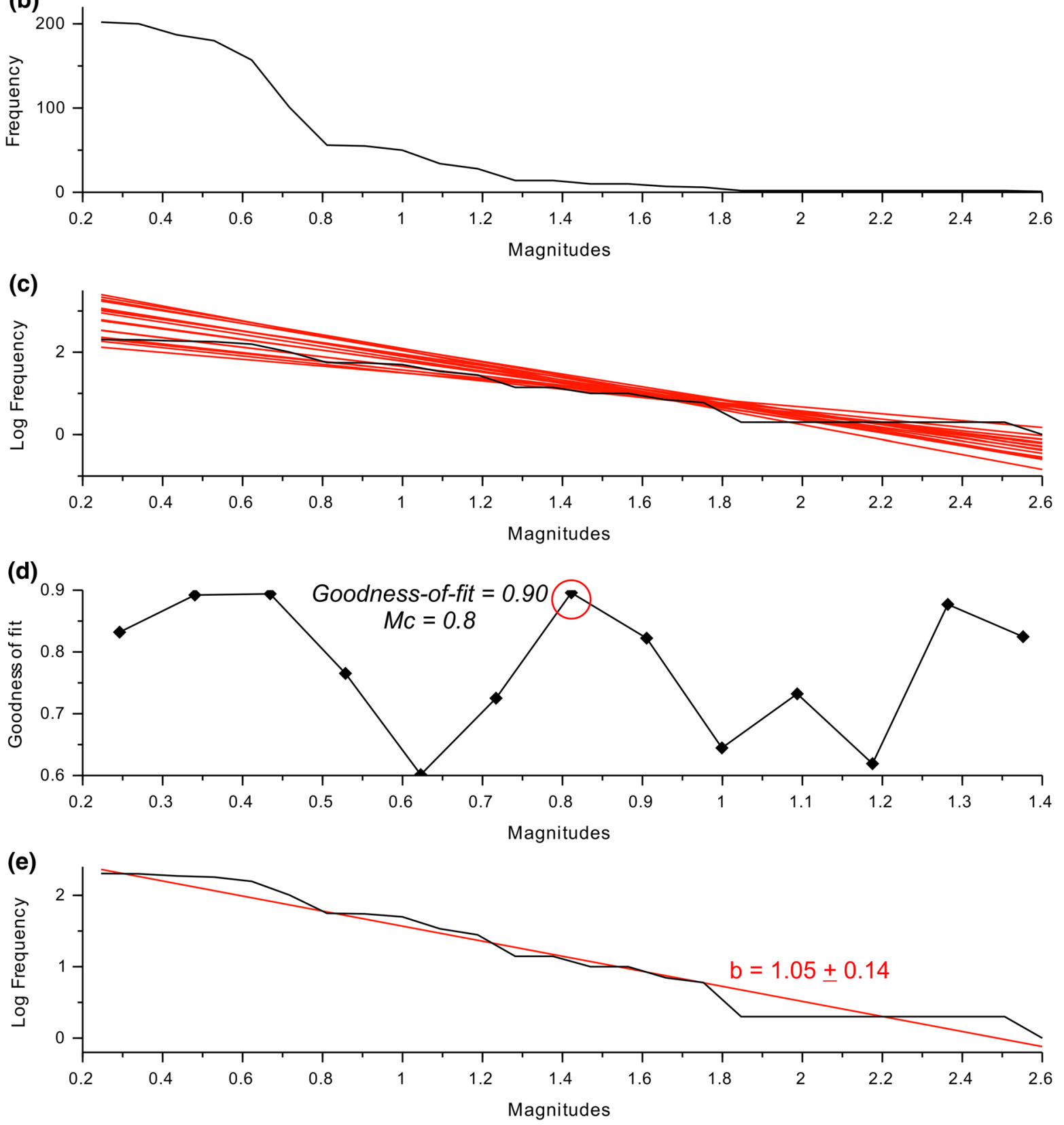
Figure 7

Data statistics for the PMG mine-the second data set (in the vicinity of the pillar): a histogram of frequency-magnitude relationship, $\mathbf{b}$ cumulative frequencies vs. magnitude, $\mathbf{c}$ considered models of frequency-magnitude relationship (red lines) and d changes corresponding the goodness-of-fit with magnitudes, e comparison of the best fit of frequency-magnitude relationship (red line) with log-frequency-magnitude distribution

elements which progressively phase up and construct a "macroscopic" self-similar state (Bowman et al. 1998). Or, in other words, rock failure in earthquakes is a process caused by stress perturbation of faults by relatively small event nucleations, thus it is ultimately brought about by a final, incremental change in stress (Foulger et al. 2017). Therefore, it can be assumed that geological and mining conditions, in the vicinity of the studied longwall field, are characterised with high heterogeneity. The observed preshocks are a small nucleation acceleration before the main stress change in the rock mass represented by the strong target tremor $\mathrm{M}_{\mathrm{L}}$ 3.7. Figure 2 shows which heterogeneities could influence the sequence. In the vicinity of the study area, there are two safety pillars and two panels related to coal seam 503 . Moreover, in the northern part, there is a fault with the throw of $40 \mathrm{~m}$, which could significantly disturb the stress regime in the area of the longwall field.

In order to quantify the degree of acceleration in the seismicity, the curvature parameters, $e$, were calculated (Bowman et al. 1998) according to formula:

$$
e=\frac{R M S_{\text {power }}}{R M S_{\text {linear }}}
$$

Table 1

Basic information about the seismic data used in the analysis

\begin{tabular}{|c|c|c|c|c|c|c|}
\hline Mine & $\begin{array}{l}\text { Number of events in } \\
\text { the foreshock sequence }\end{array}$ & $\begin{array}{l}\text { Strong event } \\
\mathrm{M}_{\mathrm{L}}(\text { energy, } \mathrm{J})\end{array}$ & Date & $\begin{array}{l}\text { Calculated minimum } \\
\text { magnitude }\end{array}$ & $\begin{array}{l}\text { Goodness } \\
\text { of fit }\end{array}$ & $b$ value \\
\hline Bobrek mine & 275 & $3.7\left(8 \times 10^{8}\right)$ & $2009-12-16$ & 1.0 & 0.90 & 1.18 \\
\hline PMG mine & 76 & $2.7\left(9 \times 10^{6}\right)$ & 2017-05-04 & 0.7 & 0.70 & 1.31 \\
\hline seam 504 & 195 & $3.6\left(5 \times 10^{8}\right)$ & 2018-01-18 & & & \\
\hline \multirow[t]{2}{*}{ PMG mine seam 405/2 } & 34 & $2.6\left(4 \times 10^{6}\right)$ & 2016-10-19 & 0.8 & 0.9 & 1.05 \\
\hline & 14 & $2.5\left(3 \times 10^{6}\right)$ & 2016-11-29 & & & \\
\hline
\end{tabular}

The curvature parameter $e$ is the ratio of RMS values obtained for power-law fitting and linear fitting (Table 2). If the data are best characterised by the power law curve, the RMS error will be the lowest and corresponding the RMS of linear fitting will be the highest, thus their ratio (curvature parameter) will become the lowest. Moreover, if the power law fit is high compared to the linear fit, the $e$ parameter will be at or near unity. It represents the situation when seismicity increases linearly (Bowman et al. 1998). Table 2 contains also values of the determination coefficient which indicate that fitting is very good and observed outcomes are replicated by the model.

These sequences represent the typical accelerating-like process of seismic energy release in a heterogeneous medium with a target event at the end. Analysing the obtained values of $e$-parameter for the data set from panel 3/503 (Table 2), one can conclude that with a radius of $700 \mathrm{~m}$, the induced seismicity produces a well-defined power-law and the studied area can be delimited by a circle with a $700 \mathrm{~m}$ radius (Fig. 2). While there is significant scattering in the region sizes, large tremors tend to be preceded by larger critical regions than in case of small events (Bowman et al. 1998). In this case, the mining tremor (target event) with $\mathrm{M}_{\mathrm{L}} 3.7$ corresponds to the critical radius of $700 \mathrm{~m}$ because the curvature parameter reached the value of 0.239 . It seems interesting whether the search radius can be compared with the source radius of the target event. The studied mining tremor radius reached $195 \mathrm{~m}$ (Kozłowska et al. 2016) calculated using Brune's source model and it is not in agreement with results for the $e$-parameter. Because the source radius provides a crude estimate of the characteristic rupture size it can be assumed that the 


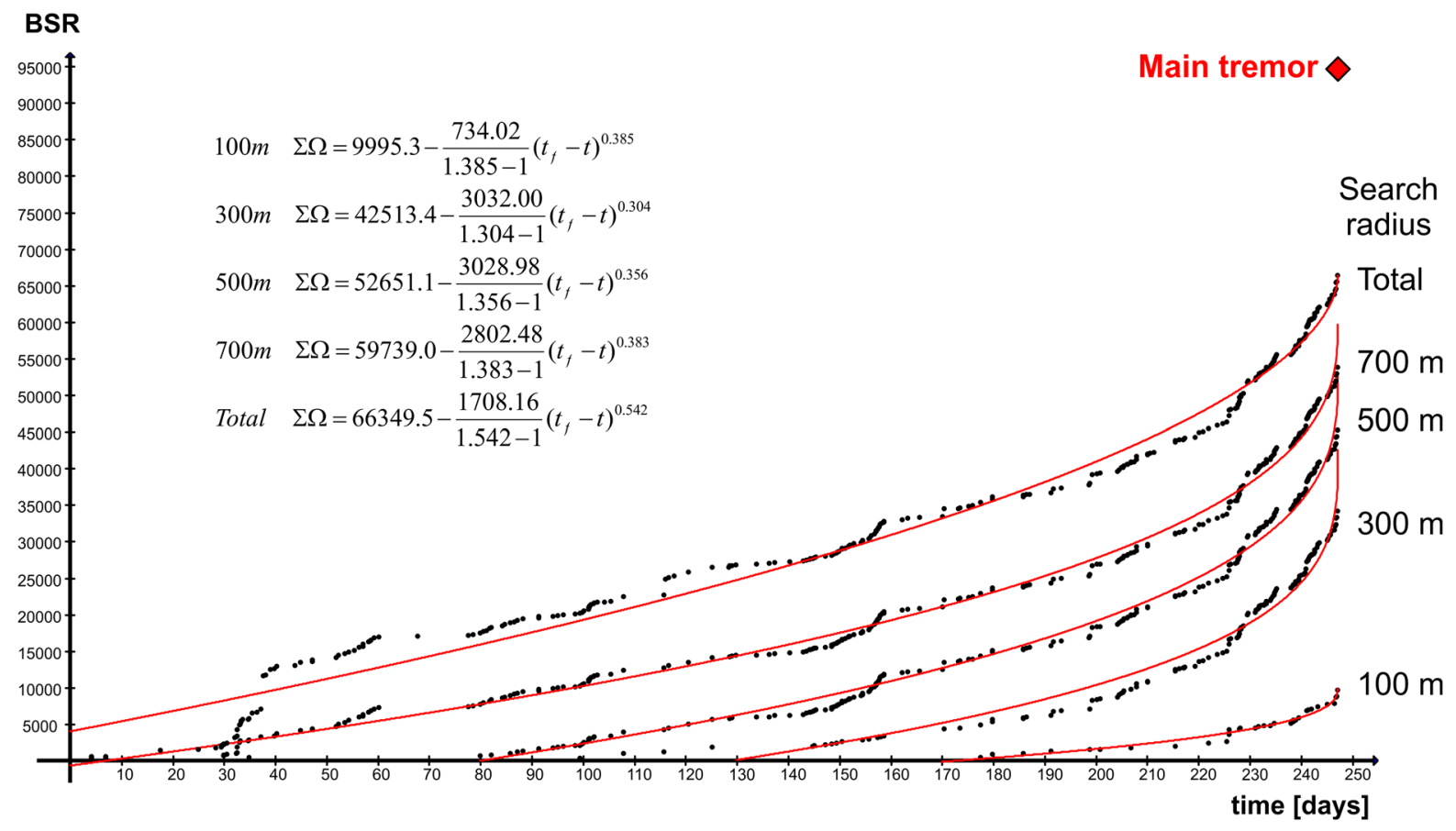

Figure 8

An example of accelerating seismic energy release without interfering events from the Bobrek mine. Five cumulative seismic energy release curves from the bottom to the top correspond to the radius of the searching area of $100 \mathrm{~m}, 300 \mathrm{~m}, 500 \mathrm{~m}, 700 \mathrm{~m}$, and the total number of observed events, respectively. Curves of power-law fitting are also shown in the figure. The red square represents the target tremor

Table 2

RMS values for power-law and linear fitting and curvature parameters of BSR for the Bobrek mine data

\begin{tabular}{|c|c|c|c|c|c|}
\hline Search radius & $100 \mathrm{~m}$ & $300 \mathrm{~m}$ & $500 \mathrm{~m}$ & $700 \mathrm{~m}$ & total \\
\hline$R^{2}$ power-law fitting & 0.97 & 0.96 & 0.99 & 0.99 & 0.98 \\
\hline$R M S_{\text {power }}$ & 437.4 & 1919.3 & 1521.6 & 1115.8 & 2199.7 \\
\hline$R M S_{\text {linear }}$ & 1081.0 & 5062.7 & 4844.9 & 4678.2 & 3922.7 \\
\hline$e$ & 0.405 & 0.379 & 0.314 & 0.239 & 0.561 \\
\hline
\end{tabular}

Bolded values represent these for the lowest curvature parameter

search radius does not have in common with the rupture zone. It can be stated that the search radius is related to present stress distribution around the entire longwall due to its value $700 \mathrm{~m}$, representing an area with diameter of $1400 \mathrm{~m}$. Furthermore, according to definition (Brehm and Braile (1999), a search radius represents the range where the precursory sequence is generated. It can be also assumed that the 700-m search radius corresponds to the entire area of the longwall panel which can be an area of nucleation process of the target event.

\subsection{Seismic Energy Release in the PMG Mine}

The second studied mine shared two data sets from two different areas: the longwall field and the longwall field exploited near the safety pillar. For both cases, the same calculations of AER functions were carried out, wherein both data sets had an interfering event and they were split into sequences (Figs. 9, 10).

Figure 9 shows the seismic energy release in the area of the longwall field in coal seam 504. The first 


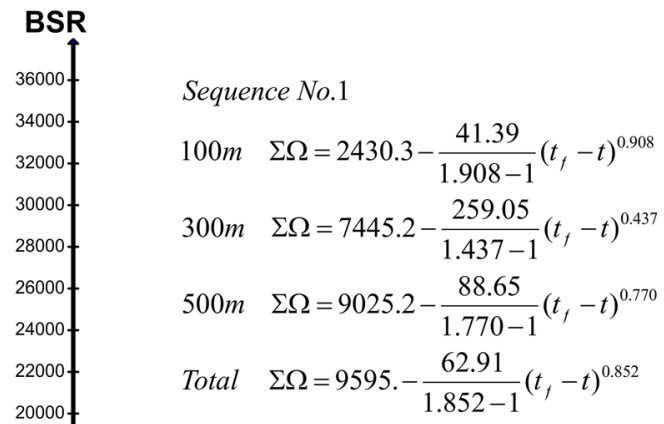

Sequence No.2

$300 m \quad \Sigma \Omega=6736.6-\frac{45.89}{1.903-1}\left(t_{f}-t\right)^{0.903}$
$500 m \quad \Sigma \Omega=13060.3-\frac{116.08}{1.818-1}\left(t_{f}-t\right)^{0.818}$
Total $\quad \Sigma \Omega=13915.8-\frac{90.10}{1.891-1}\left(t_{f}-t\right)^{0.891}$

18000

16000

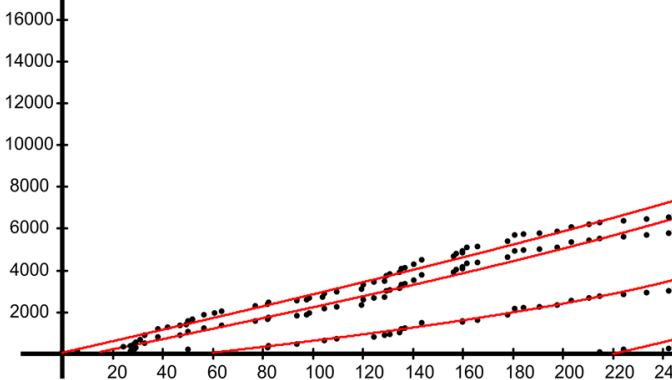

Main tremor 2.7

- Total

Sequence No. 1

$\$ 500 \mathrm{~m}$

. $300 \mathrm{~m}$

$\therefore 100 \mathrm{~m}$

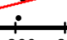

$+\dot{1}+$

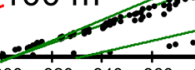

$00+320+340+360$

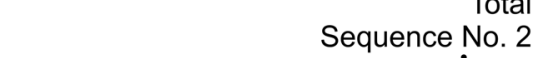

Sequence No. 2

Figure 9

An example of accelerating seismic energy release with interfering events from exploited longwall field. The cumulative seismic energy release curves from the bottom to the top correspond to the radius of the searching area of $100 \mathrm{~m}, 300 \mathrm{~m}, 500 \mathrm{~m}$, and the total number of observed events, respectively. Curves of power-law fitting are also shown in the figure. The red and green squares represent the target tremors

pre-shock sequence occurred before the $\mathrm{M}_{\mathrm{L}} 2.7$ interfering tremor and indicated that the seismicity in this area does not have a stable accelerating or deaccelerating property (according to Jiang and $\mathrm{Wu}$ 2006) due to the AER function shapes and value of the $m$-parameter for varying search radii $(100 \mathrm{~m}$, $300 \mathrm{~m}, 500 \mathrm{~m}$ and for the total number of events). The $m$-parameter for the $100-\mathrm{m}$ radius and for the total number of events is close to 1 which indicated that seismic energy release is more linear than power law.

Only the accelerating-like process is observed for the $300-\mathrm{m}$ search radius, because the $m$-parameter reached the value of 0.437 . This radius can be assumed as critical. In the first sequence, the remaining $m$-values were calculated as $0.908,0.770$ and 0.852 for the search radius lengths of $100 \mathrm{~m}$, $500 \mathrm{~m}$ and the total number of events, respectively. In the second sequence, the $m$-parameters were close to unity and reached $0.903,0.818$ and 0.891 for $300 \mathrm{~m}, 500 \mathrm{~m}$ and the total number of events, respectively, wherein the lowest value was obtained for the 500-m search radius which can be treated as the critical one. All calculations of the BSR model parameters seem to be reliable due to the high value of determination coefficients which were larger than 0.85 (Table 3).

These two sequences probably represent a situation when exploitation was carried out in a heterogeneous environment, where discontinuities were presented in surroundings of the studied area. It caused the accelerating-like process of release of seismic energy accumulated in the rock mass. This process induced a relatively strong tremor and unloaded the total stress as well as disturbed the discontinuities system in the rock mass, thereby increasing the level of the critical stress value (according to Hooke's law). Next, the proceeded exploitation started once again the accelerating-like process of seismic energy release, causing the next stress unloading-another, much stronger event due to changes in the strength properties of the rocks. 


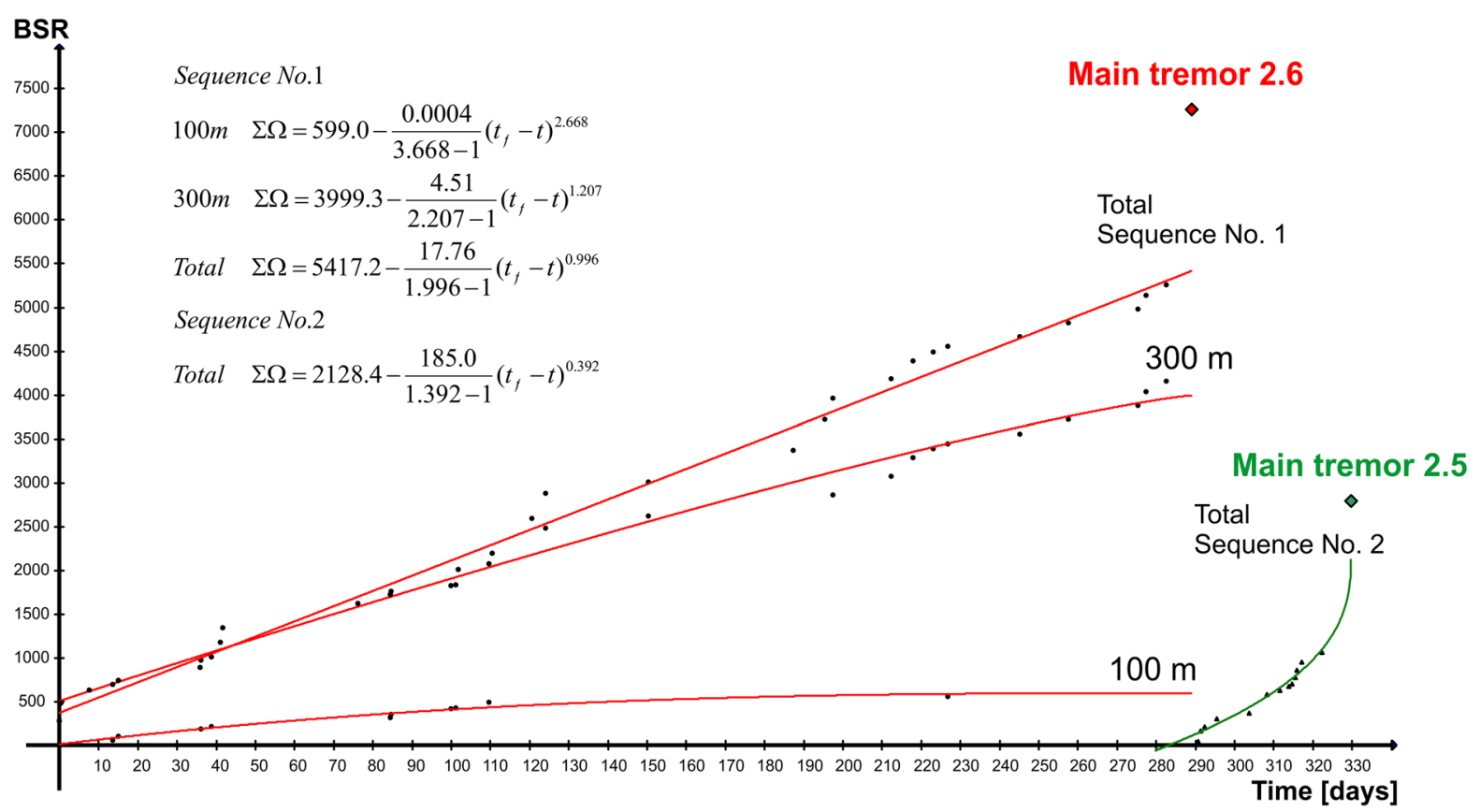

Figure 10

An example of mixed types (quiescence-like and accelerating-like) of seismic energy release with interfering events from the exploited longwall field in the vicinity of the safety pillar. The cumulative seismic energy release curves from the bottom to the top correspond to the radius of the searching area of $100 \mathrm{~m}, 300 \mathrm{~m}$ and the total number of observed events, respectively. Curves of power-law fitting are also shown in the figure. The red and green squares represent the target tremors

Table 3

RMS values for power-law and linear fitting and curvature parameters of BSR for PMG mine data (the longwall field)

\begin{tabular}{|c|c|c|c|c|c|c|c|}
\hline \multirow[t]{2}{*}{ Search radius } & \multicolumn{4}{|c|}{ Sequence 1} & \multicolumn{3}{|c|}{ Sequence 2} \\
\hline & 100 & 300 & 500 & Total & 300 & 500 & Total \\
\hline$R^{2}$ power-law fitting & 0.86 & 0.98 & 0.99 & 0.99 & 0.98 & 0.99 & 0.99 \\
\hline$R M S_{\text {power }}$ & 310.5 & 274.9 & 289.5 & 302.9 & 299.6 & 356.9 & 369.6 \\
\hline$R M S_{\text {linear }}$ & 341.7 & 539.0 & 363.3 & 335.6 & 310.4 & 455.0 & 409.1 \\
\hline$e$ & 0.909 & 0.510 & 0.797 & 0.902 & 0.965 & 0.784 & 0.904 \\
\hline
\end{tabular}

Bolded values represent these for the lowest curvature parameter

The curvature parameters were calculated for each search radius in the sequences. The results are presented in Table 3 and they confirmed that the critical radius for the first sequence is $300 \mathrm{~m}$ and it is $500 \mathrm{~m}$ for the second one, and they correspond to the target events $M_{L} 2.7$ and $M_{L} 3.6$, respectively. Here, it can be also noticed that the critical radius length increases with the size of the event. Moreover, the obtained search radiuses: $300 \mathrm{~m}$ and $500 \mathrm{~m}$ can correspond to size of exploited area of the longwall panel. Other words, the first part of the exploited panel was related to the area of nucleation process of $\mathrm{M}_{\mathrm{L}} 2.7$ target event, and second part of the panel was the nucleation process area of $\mathrm{M}_{\mathrm{L}} 3.6$ target event.

The next data set concerns exploitation near the safety pillar in coal seam 405/2, panel 2 (Fig. 10). Here, the data set was also split into two sequences as well, where the first one was finished with the 
Table 4

RMS values for power-law and linear fitting and curvature parameters of BSR for PMG mine data (the pillar)

\begin{tabular}{lllll}
\hline Search radius & \multicolumn{2}{l}{ Sequence 1 } & Sequence 2 \\
\cline { 2 - 5 } & 300 & 500 & total & Total \\
\hline$R^{2}$ power-law fitting & $\mathbf{0 . 9 6}$ & 0.99 & 0.99 & $\mathbf{0 . 9 8}$ \\
$R M S_{\text {power }}$ & $\mathbf{2 9 . 8}$ & 121.0 & 160.1 & $\mathbf{5 4 . 7}$ \\
$R M S_{\text {linear }}$ & $\mathbf{7 5 . 3}$ & 141.7 & 165.2 & $\mathbf{7 2 . 2}$ \\
$\boldsymbol{e}$ & $\mathbf{0 . 3 9 6}$ & 0.854 & 0.969 & $\mathbf{0 . 7 5 8}$ \\
\hline
\end{tabular}

Bolded values represent these for the lowest curvature parameter

interfering $\mathrm{M}_{\mathrm{L}} 2.6$ event and the second one concerned the $\mathrm{M}_{\mathrm{L}} 2.5$ event. The first sequence was larger than the second one and it represents an almost linear seismic energy release during the exploitation approaching the safety pillar. This linearity is shown by $m$-parameters which are close to unity. Moreover, the $m$-value is higher than 1.0 for search radii of $100 \mathrm{~m}$ and $300 \mathrm{~m}$, indicating that in this case the seismic energy release is a quiescence-like sequence. It can represent a more homogenous environment where uniform roof and floor rocks exist that do not affect the stress regime significantly.

After the $\mathrm{M}_{\mathrm{L}} 2.6$ target event, the rock mass system was probably changed, together with the stress regime, because the second sequence represents an accelerating-like process with the $m$-value of 0.392. This specific situation could correspond to the process of pillar damage. At the beginning, the seismicity in this area is related to random seismic energy release on discontinuities occurring in the surroundings due to deflection of the floor layers. Moreover, when the longwall face advances approaching the pillar, the seismic energy could be accumulated in the pillar zone. Next, when the critical value of stress is exceeded, the pillar is damaged creating a new system of discontinuities. Thereby, we have assumed that the rock mass system changed from nearly homogenous (less fractured) to heterogeneous (more fractured), which was manifested by the accelerating-like process in the second analysed sequence.

The calculation of the curvature parameter (Table 4) indicated that the critical search radius for $\mathrm{M}_{\mathrm{L}} 2.6$ target event was $300 \mathrm{~m}$. The short second sequence was based only on one search radius because the distances between $\mathrm{M}_{\mathrm{L}} 2.5$ target event and pre-shocks ranged of 25-212 $\mathrm{m}$. Therefore, it can be assumed that the critical search radius in this case reached ca. $200 \mathrm{~m}$. Using the same approach as above, we could state that nucleation area of first target event corresponds to area with a radius $300 \mathrm{~m}$ (the first part of longwall panel) and smaller nucleation area of the second event corresponds to ca. $200 \mathrm{~m}$ producing weaker target event.

\section{Discussion and Summary}

The presented data sets were chosen to observe different processes of BSR in varying mining conditions. The three mining areas represent: induced seismicity of the heterogeneous rock mass with no interfering event and one target event-Bobrek Mine; induced seismicity of a strongly heterogeneous rock mass with an interfering event increasing the discontinuities, thereby, increasing the level of critical stress value and producing a stronger second target event-PMG Mine, coal seam 504; and induced seismicity of a nearly homogenous rock mass in a situation where the longwall face approaches the safety pillar and produces its damage. That resulted in occurrence of the second sequence of pre-shocks with an accelerating-like behaviour due to new discontinuities in the pillar surroundings-PMG Mine, coal seam 405.

The proposed approach using BSR models allowed to approximate the behaviour of the stress regime in the rock masses surrounding the studied longwall fields. Moreover, this paper discussed a study issue that could be used to better understand the 
processes occurring during underground exploitation. The selected three examples of the coal seams are not enough to formulate a coherent theory, but the work on it should be continued. The papers of Mignan (2011), Guilhem et al. (2013) and Vallianatos and Chatzopoulos (2018) discussed the advantages and disadvantages of BSR studies in which a number of uncertainties resulting from the nature of natural earthquakes are indicated (e.g.: whether earthquakes in pre-shock sequence concern a strong earthquake nucleation process, or what is the magnitude cut-off level, etc.). In the case of seismicity occurring in mines, these problems are not likely to occur. The swarm of tremors located in a vicinity of an exploited coal seam gives a high probability that they are associated with mining operations and local stress accumulation. In addition, the analysis of mining tremors statistics allows to distinguish a relative strong event ( $>M_{L} 2.5$ ) from a swarm of weak events (from $M c$ to $M_{L}$ 2.0). However, during this study many questions also arise, for example, whether the observed phenomena are either self-organised critical processes that can be simplified as a sequence: preshocks $\rightarrow$ strong event $\rightarrow$ next sequence (a seismic cycle), or they are examples of simple critical ruptures. Bowman et al. (1998) noted that the critical rupture associated with large earthquakes (natural and global) are a small fraction of the entire history described by the self-organised criticality. However, there is no clear evidence that induced seismicity can have self-organised criticality. Some works appeared in world-wide literature (e.g.: Grasso 1993), but they did not specify it clearly. Moreover, the self-organised criticality state was related mainly to the uppermost Earth crust geological condition, but also depended on the size of the seismogenic layers, e.g.: in induced seismicity, it depended on the presence and size of the pillar (Grasso and Sornette 1998 and references cited there). Mignan (2011) widely discussed the problem of self-criticality in case of BSR acceleration. This question remains still open and the answer for natural seismicity seems to be more difficult than in the case of mining seismicity due to the assumption that nucleation area around the longwall panel is a closed system and only the mining operation causes changes in the stress regime. This is a general assumption that there are no external (natural) forces that can disturb the stress distribution in rock masses. The solution to this issue in the further studies (on more data) may be an application of the declustering technique and detection of those tremors that are induced, triggered and even naturally originated.

According to Bowman et al. (1998) and Grasso and Sornette (1998), it needs a slow driving rate and describes the jerky steady state of the system at large timescales, but it concerned the strong natural event. Therefore, can the seismicity in mining be described as having a slow driving rate with large timescales? If we assume that the timescale in the case of mining of one coal seam panel, treated as a closed system (with its surroundings), was "large enough" and the target event characterised the jerky steady state, only indication of the problem of the driving rate would be required. This slow rate could correspond to the type of seismic energy release and if the system was a quiescence-like on, it would be related to self-organised critical process. This hypothesis can be observed in the case of exploitation near the safety pillar.

On the other hand, a critical rupture occurs when the applied force reaches a critical value beyond which the system moves globally and abruptly (Bowman et al. 1998). This definition fits quite well to accelerating-like seismic energy release sequences, because they can be compared to a rock mass system which moves abruptly and globally (meaning the longwall panel with its surroundings as a whole) to a critical value of stress producing, finally, a relatively strong mining event (observed in the Bobrek mine case and in the longwall field area in the PMG mine). Therefore, the search radius (critical radius) can correspond to nucleation area of target event and thus it can suggest that this area is close to area of an exploited longwall panel. The type of release process for smaller radiuses (than the search radius) could corresponds to the seismic energy release in (power $m<1$, accelerating-like) or more homogenous (power $m>1$, quiescence-like) rock masses. For lager radiuses (than search radius) it can be assumed that the studied area cover both the area of nucleation process and rock masses, mining structure outside this area and we suggest that this part become uncertain for further interpretation. This idea is 
shown in Fig. 11 where the critical radius (red) correspond to both size of exploited longwall panel (or entire panel) and a nucleation area; and smaller radiuses (blue) represents the process of seismic energy release in heterogeneous or more homogenous environment. Black circle (Fig. 11) is a manifestation of a radius that is larger than target event radius.

However, these assumptions and suggestions do not indicate whether the observed rupture is a part of a self-organised process with a longer timescale, or a single example of the critical rupture. It should be noted that in the self-organised sequence mentioned above, the aftershocks are omitted due to the problem with aftershock distinction from the seismic catalogue and it was assumed that the aftershocks are weaker and their energy might be below the entire catalogue level. If an aftershock appeared that was used in the analysis as one of the pre-shock events, it would be also assumed that such an event become a part of the pre-shock sequence because it could have had influence on stress regime in rock mass as well.

Another aspect that can be analysed based on the observation is the relationship between the critical radius and magnitude of the target event. Such studies were reported by Bowman et al. (1998), Jaumé and
Sykes (1999) and Jiang and Wu (2006) (Fig. 12), but they concerned strong natural earthquakes. Moreover, Brehm and Braile (1998) published data in the paper that were used to estimate $\log (R) \sim$ M relationship in Fig. 12. Here, we tried to build up a similar relation for induced seismicity data and check their properties. Table 5 presents the comparison of local magnitudes and corresponding critical radiuses. Next, the relationship was calculated using linear regression on a log-normal plot (Fig. 12). The obtained equation indicated that $\log (R c) \sim 0.35 \mathrm{M}_{\mathrm{L}}$ and this scaling relation is very similar to $\log (R) \sim 0.36 \mathrm{M}$ reported by Jaumé and Sykes (1999), as well as $\log (R) \sim$ $0.44 \mathrm{M}$ reported by Bowman et al. (1998). Using the data from strong events the common relation (Fig. 12) was established yielding $\log (\mathrm{R})=0.39+$ 2.7. It might suggest that the scaling relation works in a wide range of magnitudes and it has the same application in natural and mining induced seismicity. However, the constant parameter (the intercept) in Fig. 12 showed a shift of natural earthquake series in relation to the obtained relation for mining series. The set of five points representing the mining series seems to be quite uncertain and such a data set is too small to draw a significant conclusion; it indicates,

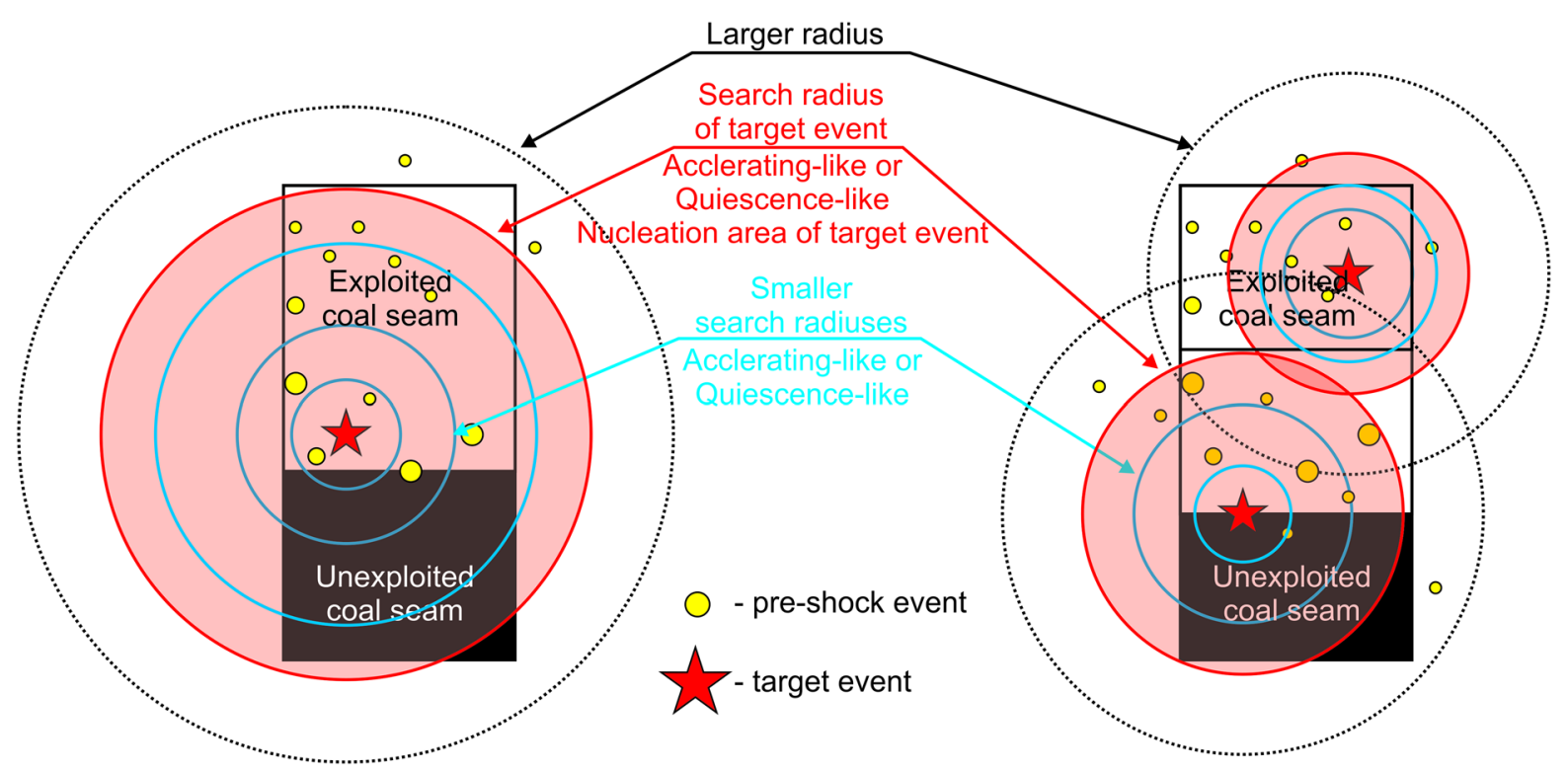

Figure 11

Models of a longwall panel with search radiuses in case of one target event and two events, red-target event radius (critical), blue smaller radiuses, black-radius larger than the target event radius 


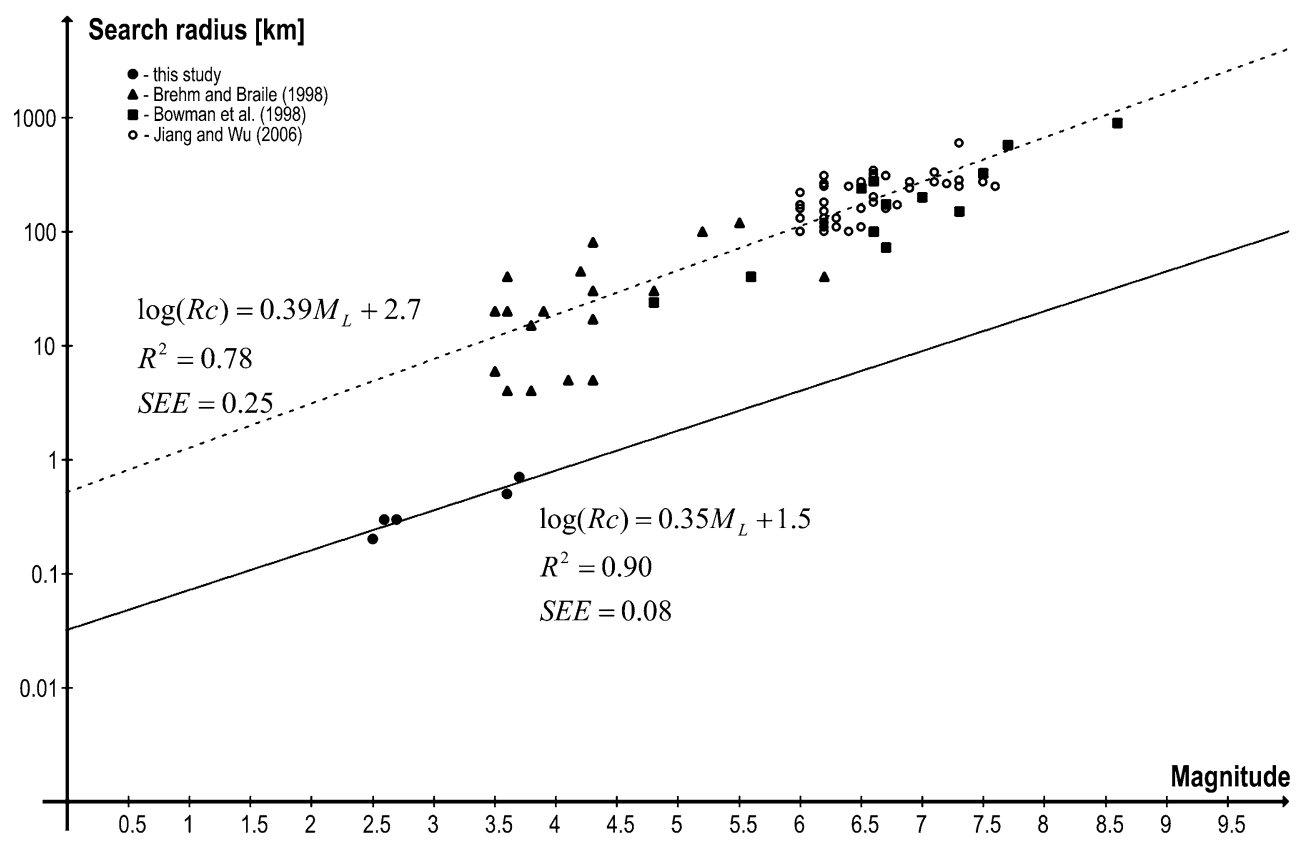

Figure 12

Comparison of target magnitude event versus logarithm of critical radius for the data obtained in this study (full dots and solid lines) with these data reported by other authors (triangles, empty dots, squares and dashed lines)

Table 5

Comparison of local magnitudes and critical radiuses

\begin{tabular}{llll}
\hline Area & $\mathrm{M}_{\mathrm{L}}$ & Critical radius, $R c(\mathrm{~m})$ & $\log (R c)$ \\
\hline Bobrek mine & 3.7 & 700 & 2.845 \\
PMG mine-longwall field seq. 1 & 2.7 & 300 & 2.477 \\
PMG mine-longwall field seq. 2 & 3.6 & 500 & 2.699 \\
PMG mine-pillar area seq. 1 & 2.6 & 300 & 2.477 \\
PMG mine-pillar area seq. 2 & 2.5 & 200 & 2.301 \\
\hline
\end{tabular}

however, another next direction for future studies on this issue.

There still remains an open question whether the analysis of seismic energy release can be a useful tool to predict strong tremors in mines. It seems that it could. Nevertheless, we have to underline that the performed calculations included known time of occurrence of target events. Additionally, the search radiuses were established based on known locations of the target events, which can make the real prediction much more questionable.
Open Access This article is distributed under the terms of the Creative Commons Attribution 4.0 International License (http://creativecommons.org/licenses/by/4.0/), which permits unrestricted use, distribution, and reproduction in any medium, provided you give appropriate credit to the original author(s) and the source, provide a link to the Creative Commons license, and indicate if changes were made.

Publisher's Note Springer Nature remains neutral with regard to jurisdictional claims in published maps and institutional affiliations. 


\section{REFERENCES}

Amorese, D. (2007). Applying a change-point detection method on frequency-magnitude distributions. Bulletin of the Seismological Society of America, 97(5), 1742-1749.

Bowman, D. D., Ouillon, G., Sammis, C. G., Sornette, A., \& Sornette, D. (1998). An observational test of the critical earthquake concept. Journal of Geophysical Research: Solid Earth, 103(B10), 24359-24372. https://doi.org/10.1029/98JB00792.

Brehm, D. J., \& Braile, L. W. (1998). Intermediate-term earthquake prediction using precursory events in the New Madrid seismic zone. Bulletin of the Seismological Society of America, 88(2), 564-580.

Brehm, D. J., \& Braile, L. W. (1999). Intermediate-term earthquake prediction using the modified time-to-failure method in southern California. Bulletin of the Seismological Society of America, 89(1), 275-293.

Cesca, S., Rohr, A., \& Dahm, T. (2013). Discrimination of induced seismicity by full moment tensor inversion and decomposition. Journal of Seismology, 17(1), 147-163. https://doi.org/10.1007/ s10950-012-9305-8.

Dahm, T., Becker, D., Bischoff, M., Cesca, S., Dost, B., Fritschen, R., et al. (2013). Recommendation for the discrimination of human-related and natural seismicity. Journal of Seismology, 17(1), 197-202. https://doi.org/10.1007/s10950-012-9295-6.

Dahm, T., Cesca, S., Hainzl, S., Braun, T., \& Krüger, F. (2015). Discrimination between induced, triggered, and natural earthquakes close to hydrocarbon reservoirs: A probabilistic approach based on the modeling of depletion-induced stress changes and seismological source parameters. Journal of Geophysical Research: Solid Earth, 120(4), 2491-2509. https://doi.org/10. 1002/2014jb011778.

Das, S., \& Scholz, C. H. (1981). Theory of time-dependent rupture in the Earth. Journal of Geophysical Research: Solid Earth, 86(B7), 6039-6051. https://doi.org/10.1029/JB086iB07p06039.

Foulger, G. R., Wilson, M., Gluyas, J., Julian, B. R., \& Davies, R. (2017). Global review of human-induced earthquakes. EarthScience Reviews, 178, 438-514. https://doi.org/10.1016/j. earscirev.2017.07.008.

Frej, A., \& Zuberek, W. M. (2008). Local effects in peak accelerations caused by mining tremors in Bytom Syncline Region (Upper Silesia). Acta Geodynamics et Geomaterialia, 5(2), 122-150.

Gibowicz, S. J. (2006). Seismic doublets and multiplets at Polish coal and copper mines. Acta Geophysica, 54(2), 142-147. https:// doi.org/10.2478/s11600-006-0014-y.

Gibowicz, S. J., \& Kijko, A. (1994). An introduction to mining seismology. San Diego: Academic Press.

Grasso, J. R. (1993). Triggering of self-organized system: Implication for the state of the uppermost crust. In R. P. Young (Ed.), Rockbursts and seismicity in mines 93: Proceedings of the 3rd international symposium, Kingston, Ontario, 16-18 August 1993 (Vol. 3). Boca Raton: CRC Press.

Grasso, J. R., \& Sornette, D. (1998). Testing self-organized criticality by induced seismicity. Journal of Geophysical Research: Solid Earth, 103(B12), 29965-29987. https://doi.org/10.1029/ 97JB01344.

Grigoli, F., Cesca, S., Priolo, E., Rinaldi, A. P., Clinton, J. F., Stabile, T. A., et al. (2017). Current challenges in monitoring, discrimination, and management of induced seismicity related to underground industrial activities: A European perspective. Reviews of Geophysics, 55(2), 310-340. https://doi.org/10.1002/ 2016RG000542.

Gross, S., \& Rundle, J. (1998). A systematic test of time-to-failure analysis. Geophysical Journal International, 133(1), 57-64. https://doi.org/10.1046/j.1365-246X.1998.1331469.x.

Guilhem, A., Bürgmann, R., Freed, A. M., \& Ali, S. T. (2013). Testing the accelerating moment release (AMR) hypothesis in areas of high stress. Geophysical Journal International, 195(2), 785-798. https://doi.org/10.1093/gji/ggt298.

Ibáñez, J. M., De Angelis, S., Díaz-Moreno, A., Hernández, P., Alguacil, G., Posadas, A., et al. (2012). Insights into the 2011-2012 submarine eruption off the coast of El Hierro (Canary Islands, Spain) from statistical analyses of earthquake activity. Geophysical Journal International, 191(2), 659-670. https://doi. org/10.1111/j.1365-246X.2012.05629.x.

IS EPOS. (2017). Episode: BOBREK. https://doi.org/10.25171/ instgeoph_pas_isepos-2017-003. https://tcs.ah-epos.eu/\#episode: BOBREK. Accessed 24 Feb 2019.

Jaumé, S. C., \& Sykes, L. R. (1999). Evolving towards a critical point: A review of accelerating seismic moment/energy release prior to large and great earthquakes. Pure and Applied Geophysics, 155, 279-305. https://doi.org/10.1007/s000240050266.

Jiang, C., \& Wu, Z. (2005). Test of the preshock accelerating moment release (AMR) in the case of the 26 December $2004 \mathrm{Mw}$ 9.0 Indonesia earthquake. Bulletin of the Seismological Society of America, 95(5), 2016-2025.

Jiang, C., \& Wu, Z. (2006). Benioff strain release before earthquakes in China: Accelerating or not? Pure and Applied Geophysics, 163, 1965-1976. https://doi.org/10.1007/s00024006-0107-1.

Kawada, Y., \& Nagahama, H. (2006). Cumulative Benioff strainrelease, modified Omori's law and transient behaviour of rocks. Tectonophysics, 424(3-4), 157-166. https://doi.org/10.1016/j. tecto.2006.03.032.

Kędzior, S. (2015). Methane contents and coal-rank variability in the Upper Silesian Coal Basin, Poland. International Journal of Coal Geology, 139, 152-164. https://doi.org/10.1016/j.coal.2014. 09.009 .

Kozłowska, M., \& Orlecka-Sikora, B. (2017). Assessment of quantitative aftershock productivity potential in mining-induced seismicity. Pure and Applied Geophysics, 174(3), 925-936. https://doi.org/10.1007/s00024-016-1432-7.

Kozłowska, M., Orlecka-Sikora, B., Rudziński, Ł., Cielesta, S., \& Mutke, G. (2016). A typical evolution of seismicity patterns resulting from the coupled natural, human-induced and coseismic stresses in a longwall coal mining environment. International Journal of Rock Mechanics and Mining Sciences, 86, 5-15. https://doi.org/10.1016/j.ijrmms.2016.03.024.

Leptokaropoulos, K., Staszek, M., Cielesta, S., Urban, P., Olszewska, D., \& Lizurek, G. (2017). Time-dependent seismic hazard in Bobrek coal mine, Poland, assuming different magnitude distribution estimations. Acta Geophysica, 65(3), 493-505. https://doi.org/10.1007/s11600-016-0002-9.

Lizurek, G. (2017). Full moment tensor inversion as a practical tool in case of discrimination of tectonic and anthropogenic seismicity in Poland. Pure and Applied Geophysics, 174(1), 197-212. https://doi.org/10.1007/s00024-016-1378-9.

Marcak, H., \& Mutke, G. (2013). Seismic activation of tectonic stresses by mining. Journal of Seismology, 17(4), 1139-1148. https://doi.org/10.1007/s10950-013-9382-3. 
Mignan, A. (2011). Retrospective on the accelerating seismic release (ASR) hypothesis: Controversy and new horizons. Tectonophysics, 505(1-4), 1-16. https://doi.org/10.1016/j.tecto. 2011.03.010.

Mulargia, F., \& Bizzarri, A. (2014). Anthropogenic triggering of large earthquakes. Scientific Reports, 4(6100), 1-7. https://doi. org/10.1038/srep06100.

Mutke, G., \& Pierzyna, A. (2011). The time dependent changes of $\mathrm{b}$ value in the Gutenberg-Richter formula for the evaluation of seismic hazard in longwalls 2 and 3 of the Bobrek-Centrum mine. Research Reports of Central Mining Institute: Mining and Environment, 4(3), 298-309. (in Polish).

Patyńska, R., \& Stec, K. (2017). Regional rockburst inidicator for structural units of Upper Silesia Coal Basin. Studia Geotechnica et Mechanica, 39(3), 27-37. https://doi.org/10.1515/sgem-20170027.

Stec, K. (2007). Characteristics of seismic activity of the Upper Silesian Coal Basin in Poland. Geophysical Journal International, 168(2), 757-768. https://doi.org/10.1111/j.1365-246X. 2006.03227.x.

Sykes, L. R., \& Jaumé, S. C. (1990). Seismic activity on neighbouring faults as a long-term precursor to large earthquakes in the San Francisco Bay area. Nature, 348(6302), 595-599.
Vallianatos, F., \& Chatzopoulos, G. (2018). A complexity view into the physics of the accelerating seismic release hypothesis: Theoretical principles. Entropy, 20(10), 754. https://doi.org/10. 3390/e20100754.

Varnes, D. J. (1983). Time-deformation relations in creep to failure of earth materials. In: Proceedings of 7th Southeast Asian geotechnical conference 2 (pp. 107-130).

Varnes, D. J. (1989). Predicting earthquakes by analyzing accelerating precursory seismic activity. Pure and Applied Geophysics, 130(4), 661-686. https://doi.org/10.1007/ BF00881603.

Voight, B. (1989). A relation to describe rate-dependent material failure. Science, 243(4888), 200-203.

Wiemer, S., \& Wyss, M. (2002). Mapping spatial variability of the frequency-magnitude distribution of earthquakes. Advances in Geophysics, 45, 259-V.

Wojtecki, Ł., Mendecki, M. J., Zuberek, W. M., \& Knopik, M. (2016). An attempt to determine the seismic moment tensor of tremors induced by destress blasting in a coal seam. International Journal of Rock Mechanics and Mining Sciences, 83, 162-169. https://doi.org/10.1016/j.ijrmms.2016.01.002. 